\title{
Diferentes pronúncias em uma língua não sonora? Um estudo da variação na produção de sinais da libras
}

\author{
Different pronunciations in a silent language? A study of \\ variation in the production of Brazilian Sign Language signs
}

\author{
André Nogueira XAVIER* \\ Plínio Almeida BARBOSA**
}

\section{RESUMO}

Estudos fonético-fonológicos sobre a língua de sinais americana (ASL) demonstraram que os itens lexicais dessa língua se constituem de unidades distintivas (parâmetros) e que estas, por sua vez, podem apresentar variação em sua manifestação concreta. Pouco se sabe sobre os parâmetros constitutivos dos sinais da língua brasileira de sinais (libras), tampouco sobre sua variação. Este trabalho representa um primeiro passo rumo a um entendimento de como se dá a variação na produção de sinais da libras a partir do estudo das produções, por 12 sinalizadores, de 60 sinais dessa língua. A análise dessas produções, eliciadas através de imagens combinadas com glosas em português, não apenas ratificou a ocorrência da variação inter-sujeito nos parâmetros configuração de mão, localização, movimento, orientação, número de mãos e marcações não-manuais, observada na sinalização espontânea, mas revelou também variação em outros aspectos articulatórios dos sinais, entre os quais está o contato entre os articuladores. Além disso, o estudo também evidenciou a ocorrência de variação intra-sujeito em todos os parâmetros analisados.

Palavras-chave: libras; parâmetros articulatórios; variação inter-sujeito; variação intra-sujeito.

* Doutor em Linguística pela Universidade Estadual de Campinas (Unicamp).

** Doutor em Signal-Image-Parole/Option Parole pelo Institut de la Communication Parlée e Institut National Polytechnique de Grenoble, França. Professor Associado do Departamento de Linguística do Instituto de Estudos da Linguagem (Unicamp) e pesquisador do Conselho Nacional de Desenvolvimento Científico (CNPq) (301387/2011-7). 


\section{ABSTRACT}

Research on American Sign Language (ASL) phonetics and phonology has shown that signs are made up of distinctive units (parameters) and that these units can exhibit variation in their concrete manifestation. Little is known about Brazilian Sign Language (Libras) distinctive units and their variation. This study represents a first step toward a better understanding of variation in Libras signs, drawing on the analysis of 60 signs as produced by 12 deaf subjects. The analysis of these productions, elicited through images combined with glosses in Portuguese, not only confirmed the occurrence of variation in the handshape, location, movement, orientation, non-manuals and number of hands across subjects, as observed in spontaneous signing, but also revealed variation in other articulatory aspects such as contact. In addition, this study documents variation within the same subject regarding all parameters analyzed.

Key-words: Libras; articulatory parameters; variation across subjects; variation within subjects.

\section{Introdução}

O uso dos termos fonética, fonologia, ou mesmo pronúncia em referência a línguas que se manifestam visualmente, e não sonoramente, pode causar um certo estranhamento no leitor com pouca ou nenhuma familiaridade com as línguas de sinais. No entanto, a prática entre pesquisadores dessas línguas tem sido empregar a mesma terminologia utilizada na descrição e análise das línguas orais, quando esta adequadamente designa aspectos semelhantes entre esses dois tipos de língua (BATTISON, 1974; LIDDEL; JOHNSON, 1989) ${ }^{1}$. Dessa forma, quando falamos neste artigo de diferentes pronúncias dos sinais ${ }^{2}$ da língua brasileira de sinais (libras), referimo-nos às formas distintas que estes podem assumir nas produções de diferentes sinalizadores ou de um mesmo sinalizador, sem que isso represente qualquer alteração em seu significado.

1. Stokoe (1960) cunhou os termos quirologia e quirema (do grego 'keir', mão) e propôs seu uso para fazer referência ao que seria, respectivamente, os correlatos da fonologia e do fonema nas línguas de sinais. Entretanto, essa proposta não ganhou aceitação nos trabalhos que se seguiram ao dele. 
Com exceção da análise preliminar de Xavier (2011), não existem estudos que investiguem mais aprofundadamente a variação na pronúncia dos sinais da libras. Diante disso, este trabalho pretende dar um primeiro passo nessa direção, descrevendo os padrões de variação identificados na análise de 60 sinais dessa língua, bem como quantificando a manifestação desses padrões nas produções dos 12 sujeitos.

Para tanto, organizamos o presente trabalho da seguinte forma. Na seção 2, sumarizamos os estudos sobre os principais parâmetros articulatórios dos sinais da língua de sinais americana (ASL, de American Sign Language). Na seção 3, discutimos alguns trabalhos sobre a variação nos parâmetros articulatórios nessa mesma língua. Já na seção 4, descrevemos o método de coleta dos dados de libras e os estímulos empregados em nosso experimento. Por fim, na seção 5 reportamos e, na seção 6, discutimos os resultados obtidos através da análise das produções dos sujeitos de nosso experimento.

\section{As unidades sublexicais dos sinais}

Stokoe (1960) foi o primeiro pesquisador a defender, do ponto de vista da Linguística, que as línguas de sinais são línguas naturais. Ele evidenciou que essas línguas partilham com as línguas orais princípios estruturais. Stokoe demonstrou que os sinais, itens lexicais das línguas sinalizadas, ao contrário do que se pensava em sua época, não são desenhos holísticos feitos no ar. Conforme demonstrou, os sinais, semelhantemente às palavras das línguas faladas, são decomponíveis em unidades menores, ou aspectos, de três tipos, a saber, configuração de mão, localização e movimento. A configuração de mão consiste na disposição dos dedos durante a produção de um sinal. Já a localização refere-se ao lugar em que um sinal é produzido. Por fim, o movimento diz respeito à forma como a mão se move quando um determinado sinal é articulado.

Com base na análise de sinais da ASL, Stokoe demonstrou que, assim como a classe das consoantes e das vogais nas línguas orais, as unidades sublexicais que propôs se constituem de um número finito de possíveis especificações ${ }^{3}$. De acordo com o autor, na ASL, existem 
19 diferentes tipos de configuração de mão, 12 diferentes localizações e 24 tipos de movimento ${ }^{4}$. Como consequência disso, a formação de todos os sinais que compõem o léxico da ASL depende da capacidade recombinativa dessas diferentes especificações, semelhantemente ao que acontece com os fonemas ${ }^{5}$ das línguas orais.

A argumentação de Stokoe a favor do estatuto de língua natural das línguas sinalizadas não se sustentou apenas na sua demonstração de que os sinais são decomponíveis em unidades finitas e recombinativas. Stokoe também fundamentou sua tese no valor distintivo das especificações de cada um dos aspectos sublexicais dos sinais. $\mathrm{O}$ autor demonstrou isso através de pares mínimos, ou seja, pares de sinais da ASL que se opõem lexicalmente com base em uma única diferença em suas formas. Precisamente, com base em diferentes especificações da configuração de mão, ou da localização, ou do movimento de cada sinal do par, tal como acontece com os pares de sinais da libras na Figura 1.

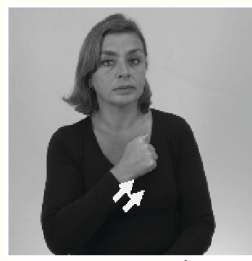

(a) CANADÁ

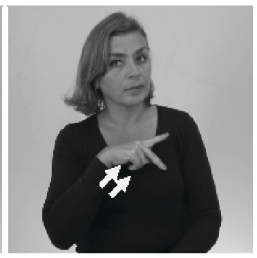

vs PALMEIRAS (time)

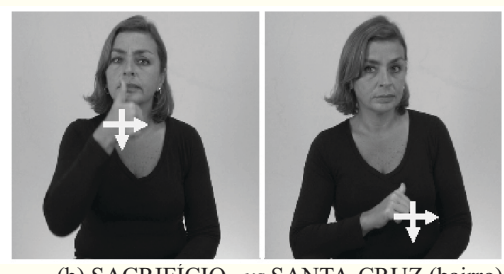

(b) SACRIFICIO vs SANTA-CRUZ (bairro)

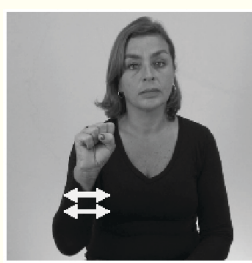

(c) SOGR@

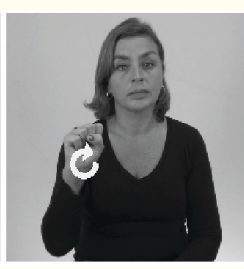

SOLTEIR@

Figura 1: Pares mínimos em que o contraste semântico se estabelece com base (a) na configuração, (b) na localização e (c) no movimento

4. Autores subsequentes não parecem concordar com o número de especificações possíveis para cada um dos aspectos articulatórios constitutivos dos sinais, apresentando, em geral, números maiores (para uma discussão a esse respeito ver LIDDEL, 1982, 373). Entretanto, tal fato não invalida a tese de Stokoe de que as possíveis especificações, tal como os fonemas nas línguas orais, são finitas.

5. Há muito debate na literatura sobre o estatuto fonológico dos parâmetros. Na visão de Stokoe e seus seguidores, eles são fonemas, diferentemente, na visão de Liddell e Johnson (1989), com exceção do movimento, eles são traços. 
Além disso, o autor atestou que, semelhantemente ao que acontece com os fonemas das línguas orais, as especificações de cada um dos aspectos que propôs podem se realizar concretamente de formas diferentes, sem que isso altere o significado do sinal ${ }^{6}$. Com isso, Stokoe apontou mais uma característica da ASL que a assemelha às línguas orais: a ocorrência de alofonia.

A partir do trabalho seminal de Stokoe, seguiu-se o trabalho de outros pesquisadores que, entre várias contribuições, expandiram o inventário de unidades sublexicais das línguas de sinais, ou parâmetros, como muitos destes passaram a chamá-las. Dentre esses trabalhos, destacam-se o de Battison (1974), Klima e Bellugi (1979) e Liddell e Johnson (1989).

Battison identificou pares de sinais na ASL que se opõem lexicalmente por apresentarem a palma da mão voltada para diferentes direções. Com base nisso, ele propôs a inclusão da orientação no rol de unidades contrastivas dessa língua. Já Klima e Bellugi propuseram o parâmetro arranjo das mãos, aqui designado como número de mãos ${ }^{7}$. Assim como Battison, os autores fundamentaram a inclusão de tal parâmetro na identificação de pares mínimos na ASL em que o contraste se estabelece unicamente pelo número de mãos (uma ou duas) com que cada sinal do par é articulado. Por fim, Liddell e Johnson propuseram a inclusão do parâmetro marcações não-manuais, por observarem que existem sinais na ASL cuja realização envolve não apenas atividades das mãos, mas também atividades de outras partes do corpo, sobretudo da face. Apesar de não citarem casos de contrastes lexicais estabelecidos unicamente com base nesse parâmetro, pares mínimos envolvendo marcações não-manuais são mencionados na literatura (BRENNAN,

6. Stokoe (1960) designa as diferentes realizações de um quirema (chamados aqui de especificações) por alóquiros.

7. Na verdade, para Klima e Bellugi (1979), o arranjo das mãos é um subparâmetro do parâmetro configuração de mão. Eles o tratam assim, por considerarem que, diferentemente da configuração de mão, o número de contrastes lexicais estabelecidos unicamente por meio do número de mãos é bem menor e, geralmente, entre sinais semanticamente relacionados. Klima e Bellugi citam outros subparâmetros tais como o contato e a região da mão (que faz contato com o corpo). Em virtude de nossos dados não abrangerem casos de variação nesses dois aspectos articulatórios, eles não serão discutidos aqui. 
1992) ${ }^{8}$. Como indicam os pares de sinais na Figura 2, a direção para qual a mão é orientada, o número de mãos empregadas na produção de um sinal e a presença de alguma marcação não-manual também são contrastivos na libras.

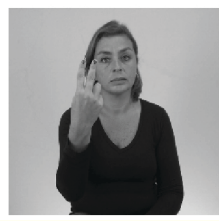

(a) DOIS

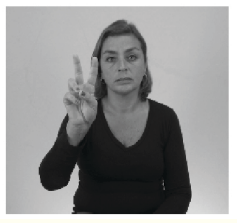

LETRA-V

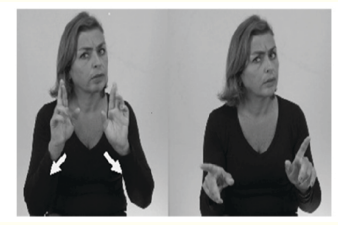

(b) DIFERENTE

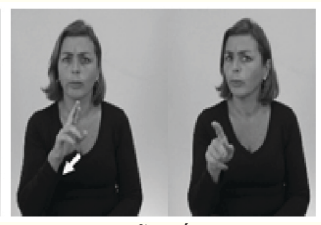

NÃO-É

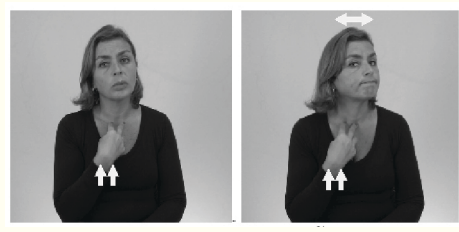

(c) OCUPAD@ vs NÃO-PODER

Figura 2: Pares mínimos em que o contraste semântico se estabelece com base (a) na orientação da palma, (b) no número de mãos e (c) nas marcações nãomanuais

\section{A variação na realização dos parâmetros sublexicais dos sinais}

A variação na realização das especificações dos parâmetros articulatórios dos sinais também vem sendo investigada na ASL. Dentre os trabalhos que descrevem e analisam a variação no parâmetro configuração de mão está o de Battison et al. (1975), Hoopes (1998) e Lucas et al. (2001).

8. Alguns sinais requerem como marcação não-manual atividades especificamente da boca. Entre as atividades da boca que considera parte do sinal, Sandler (2009) cita o que ela chama de componente oral (mouth component) e oralização (mouthing). A oralização consiste na articulação (em geral desacompanhada de vocalização) total ou parcial da palavra da língua oral falada pela comunidade ouvinte majoritária em que uma determinada comunidade surda está inserida. De acordo com Sandler, esse recurso é usado na língua de sinais israelense, entre outras razões, para desambiguar dois significados de um mesmo sinal. Já o componente oral se refere a movimentos da boca desconexos da oralização de palavras da língua oral e que, por essa razão, a nosso ver, podem ser considerados nativos. 
Battison, Markowicz e Woodward (1975) investigaram a variação que diz respeito à distensão ou não do polegar na realização de duas configurações de mão na ASL: a configuração de mão em 1 (indicador distendido, demais fechados) e a configuração de mão em U (dedos indicador e médido distendidos e unidos pelas laterais, demais fechados). Os autores caracterizam tal fenômeno como um caso de mudança em curso na ASL. Segundo eles, embora essa variação seja comumente observada em sinalizações espontâneas, ela não aparece nem em sinalizações registradas em vídeos produzidos 60 anos antes da publicação de seu trabalho, nem em materiais didáticos de ASL em que, tipicamente, só figuram as formas tidas como padrão. Os autores identificaram fatores que inibem e outros que favorecem esse processo ${ }^{9}$. Entre os fatores favorecedores, eles citam a presença de movimento de girar do pulso e a indexicalidade do sinal, ou seja, se o sinal é contíguo ou não ao seu referente. Já entre os fatores inibidores, eles apontam a distenção do dedo médio (que distingue as duas configurações em questão) e a localização no centro da face.

Já Hoopes (1998) investigou uma outra variação na realização da configuração de mão de sinais da ASL: a distensão ou não do dedo mínimo. Ele se baseou na análise da sinalização de uma surda nativa de ASL em situações em que dialogava com interlocutores com quem tinha maior ou menor grau de intimidade. Os resultados do estudo mostraram que a maior intimidade com o interlocutor parece ter favorecido uma maior ocorrência da distenção do dedo mínimo. Além disso, fatores de ordem gramatical (pertencer à categoria verbal) e prosódica (apresentar repetição, anteceder uma pausa ou ser alongado) também se mostraram relevantes. Interessantemente, Hoopes não encontrou evidências de que a variação na distensão do dedo mínimo na produção de alguns sinais da ASL decorre da influência do sinal precedente ou seguinte (assimilação ou coarticulação).

Lucas et al. (2001), por sua vez, analisaram um caso de variação na configuração de mão em sinais da ASL que, diferentemente dos dois discutidos anteriormente, não diz respeito apenas à variação em subaspectos desse parâmero (distenção ou não do polegar ou do dedo mínimo), mas também à configuração como um todo. Os autores identificaram

9. Para uma discussão mais detalhada acerca do polegar, ver Johnson e Liddell (2012). 
em seu estudo, que envolveu mais de 200 surdos de sete diferentes localidades dos Estados Unidos, quatro variantes para a configuração de mão em 1 (indicador distendido, demais fechados) empregada na forma de citação dos sinais estudados. Além da forma de citação, as configurações de mão identificadas são: em L (indicador e polegar distendidos, demais fechados), em 5 (dedos abertos e espalmados), em 4 (polegar fechado, demais abertos e espalmados) e em X (indicador em gancho, demais fechados). Esse estudo revelou que as variantes da configuração de mão em 1 não apresentam a mesma frequência: 1 , L e 5 constituem $95 \%$ dos casos, ao passo que 4 e X aparecem apenas nos $5 \%$ restantes. Além disso, esse estudo mostrou que a configuração de mão em 1 não é a mais frequente, apesar de ser a configuração da forma de citação nos sinais analisados. Ela foi empregada em apenas $40 \%$ das vezes ${ }^{10}$. Um outro achado interessante desse trabalho é que a assimilação ou coarticulação (influência da configuração de mão do sinal precedente e/ou seguinte), apesar de ser um fator relevante na determinação da variante empregada, não se mostrou como o mais importante. Foi a categoria gramatical do sinal que se revelou como o fator de primeira ordem, à qual se somaram fatores extra-linguísticos como idade, classe social e região de origem.

Dentre os trabalhos que tratam da variação na localização de sinais da ASL, pode-se citar o de Woodward et al. (1976) e o de Liddell e Johnson (1989). Woodward e colegas analisaram sete sinais da ASL cuja localização varia entre a face e a mão não-dominante. Por considerarem que esse fenômeno se relaciona a fatores extra-linguísticos, os autores selecionaram os 45 sujeitos de seu estudo levando em conta seu local de residência (New Orleans vs. Atlanta), sua etnia (branco vs. negro) e idade (abaixo e acima de 50 anos). O estudo revelou que a procedência e a etnia são relevantes na explicação da variação em questão. Sinalizadores de New Orleans usam mais a variante produzida na face do que sinalizadores de Atlanta, que empregam mais a variante

10. Para uma visão mais detalhada dos subparâmetros envolvidos na realização das configurações de mão da ASL, ver Johnson e Liddell (2011). Embora o foco dos autores seja a descrição de seu sistema de transcrição fonética da configuração de mão, a ilustração do sistema através de dados, em grande parte, da ASL permite-nos observar a grande gama de características desse aspecto articulatório que podem variar na realização concreta dos sinais. 
articulada na mão não-dominante. Sinalizadores brancos preferem a variante realizada na face à variante articulada na mão não-dominante. Diferentemente, sinalizadores negros apresentam frequências mais parecidas para essas duas variantes. Casos como esse, ou seja, em que uma localização mais alta pode ser realizada em uma localização mais baixa, são designados por Liddell e Johnson de redução. Os autores incluem nessa categoria também casos em que uma localização central da face é realizada em outra mais lateral da mesma. Segundo esses autores a redução é um processo bastante comum na sinalização informal.

Finalmente, a variação no parâmetro número de mãos na ASL também já foi documentada por alguns autores. Esses trabalhos se concentraram nos casos em que sinais tipicamente de duas mãos são realizados com apenas uma (STOKOE, 1960; BATTISON, 1974; FRIEDMAN, 1975; PADDEN; PERLMUTTER, 1987). Stokoe e Friedman citam alguns fatores extra-linguísticos como responsáveis por esse processo. Entre esses fatores, segundo ambos os autores, está a informalidade, o cansaço e a indisponibilidade de uma das mãos (por exemplo, quando uma das mãos está segurando um objeto) ${ }^{11}$. Friedman acrescenta a esse rol a taxa de elocução. Diferentemente, Battison, e Padden e Perlmutter focalizam as restrições fonológicas que regem o que Battison denomina apagamento de articulador e Padden e Perlmutter chamam de queda da mão fraca (weak drop). De acordo com com esses autores, o processo em questão só se aplica a sinais em que as mãos se movem simultaneamente. Em outras palavras, sinais realizados com movimento alternado das mãos não podem ter sua mão não-dominante apagada.

A variação no número de mãos na ASL já foi também objeto de estudos sociolinguísticos. Woodward e DeSantis (1977) investigaram a variação em sinais tipicamente produzidos com duas mãos baseados em dados coletados de duas faixas etárias (abaixo ou acima de 47 anos), duas etnias (brancos e negros) e duas diferentes regiões dos Estados Unidos (Atlanta e Nova Orleans). O estudo revelou que sinalizadores brancos jovens empregam mais a forma com uma mão do que sinali- 
zadores brancos mais velhos. Já os sinalizadores negros, tanto jovens quanto idosos, empregaram, de forma geral, mais as formas com duas mãos. Com base nesses resultados, Woodward e DeSantis evidenciam a existência de uma diferença socioletal na ASL entre sinalizadores brancos e negros. Segundo os autores, a variedade da ASL usada pelos surdos negros difere da empregada pelos surdos brancos em virtude de a primeira utilizar mais a forma de duas mãos, considerada, com base em registros históricos, como a variante mais antiga.

Com exceção do estudo preliminar de Xavier (2011), a variação na realização dos parâmetros dos sinais da libras ainda não foi investigada. Como dito anteriormente, este trabalho representa um primeiro passo nessa direção. Os trabalhos aqui sumarizados nos serviram como um guia para o levantamento de casos de variação na pronúncia dos sinais da libras. Entretanto, como se verá, identificamos em nossos dados alguns padrões de variação não mencionados na literatura sobre a ASL. Além disso, identificamos casos de variação intra-sujeito também não discutidos nos trabalhos aqui sumarizados.

\section{Método}

\subsection{Sujeitos}

O experimento foi realizado com 12 sinalizadores surdos, seis homens e seis mulheres, com idade variando entre 17 e 60 anos. Todos eles nasceram e vivem na cidade de São Paulo. Apenas dois sujeitos podem ser considerados sinalizadores nativos. Um deles nasceu de pais surdos e o outro, apesar de ter nascido de pais ouvintes, tem um irmão surdo mais velho com quem aprendeu libras desde pequeno. Os outros dez sujeitos são filhos de pais ouvintes não sinalizadores e, por isso, só puderam aprender libras na escola ou fora dela através do contato com outros surdos sinalizadores. O início do contato desses dez sujeitos com a libras aconteceu entre dois e 19 anos de idade. Todos os sujeitos reportaram ter bastante contato com outros surdos sinalizadores. Em relação ao seu nível de instrução e à sua ocupação, nove sujeitos têm nível superior e sete trabalham como instrutores de libras. Ademais da procedência e, obviamente, da surdez e do conhecimento da libras, o recrutamento dos sujeitos não seguiu nenhum outro critério. 


\subsection{Estímulos}

Os sinais empregados como estímulos no experimento aqui descrito foram coletados através da observação de usos espontâneos da libras por diferentes sinalizadores surdos. Eles constituem casos de sinais que variam em um dos seis parâmetros articulatórios discutidos na seção 2, ou seja, na configuração de mão, localização, movimento, número de mãos, orientação, e marcações não-manuais. Depois de termos observado seu uso, anotamos esses sinais e posteriormente os categorizamos e os subcategorizamos segundo o tipo de variação que apresentam. Apesar disso, como se verá na subseção seguinte, os estímulos deste experimento foram apresentados em ordem aleatória, de modo a não tornar evidente para os sujeitos as categorias de variação que estavam sendo testadas.

Como mostra o Quadro 1 e as imagens nas Figuras 3-10, incluímos entre os 60 estímulos 33 sinais que observamos variar em sua configuração de mão. Conforme mostra o mesmo quadro, a variação nesse parâmetro apresenta diferentes padrões. Há sinais cuja configuração de mão varia em virtude de certos sinais (1) poderem ser produzidos com pelos menos duas diferentes configurações nativas, ou (2) por poderem ser articulados com uma configuração de mão nativa (não relacionada com o português escrito) ou com uma configuração de mão inicializada (relacionada à inicial da palavra correspondente em português) ${ }^{12}$, ou ainda (3) por poderem ser produzidos com apenas uma configuração ou com duas, através da mudança de uma para a outra; por apresentarem ou não (4) o polegar ou (5) o dedo mínimo distendido; (6) por exibirem diferentes ordens para as duas configurações que os constituem (metátese); ou, ainda, no caso de sinais feitos com duas mãos, por

12. Brentari (2001) designa sinais da ASL formados a partir do alfabeto manual por sinais não-nativos. Entre esses sinais, segundo a autora, estão os chamados sinais inicializados, caracterizados por apresentarem uma configuração de mão que, no alfabeto manual, corresponde à primeira letra da palavra do inglês, em seu caso, comumente associada ao sinal. Adaptando a terminologia empregada por Brentari aos casos aqui discutidos, chamamos de configurações inicializadas aquelas que, como nos sinais inicializados, correspondem, no alfabeto manual da libras, à primeira letra da palavra em português normalmente associada ao sinal. Chamamos de configurações de mão nativas aquelas que, diferentemente das inicializadas, não apresentam nenhuma relação aparente com a língua portuguesa e que, portanto, devem ter se originado seguindo princípios da própria libras. 
apresentarem ou não (7) ambas as mãos com a mesma configuração, ou (8) configurações diversas na mão não-dominante.

Quadro 1: Estímulos usados para a eliciação de variação no parâmetro configuração de mão

\begin{tabular}{|c|c|c|c|c|c|c|c|c|}
\hline $\begin{array}{c}(1) \\
\text { Diferentes } \\
\text { onfigurações } \\
\text { nativas }\end{array}$ & $\begin{array}{c}(2) \\
\text { Configura- } \\
\text { ção nativa e } \\
\text { configuração } \\
\text { inicializada }\end{array}$ & $\begin{array}{c}\text { (3) } \\
\text { Uma ou } \\
\text { duas conf- } \\
\text { gurações }\end{array}$ & $\begin{array}{c}\text { (4) } \\
\text { Polegar } \\
\text { destacado } \\
\text { ou não }\end{array}$ & $\begin{array}{c}(5) \\
\text { Dedo } \\
\text { mínimo } \\
\text { destacado } \\
\text { ou não }\end{array}$ & $\begin{array}{c}\text { (6) } \\
\text { Metátese }\end{array}$ & \begin{tabular}{|c|}
$(7)$ \\
Configurações \\
idênticas ou \\
não nas duas \\
mãos
\end{tabular} & $\begin{array}{c}(8) \\
\text { Diferentes } \\
\text { configu- } \\
\text { raões na } \\
\text { mão não- } \\
\text { dominante }\end{array}$ & Total \\
\hline 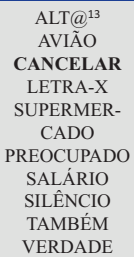 & $\begin{array}{c}\text { DESCOBRIR } \\
\text { ELEVADOR } \\
\text { EMPRESA } \\
\text { FALS@ } \\
\text { FUSCA } \\
\text { PESSOA } \\
\text { RESPEITAR } \\
\text { TEXTO }\end{array}$ & NATAL & $\begin{array}{c}\text { BRINCAR } \\
\text { CHOCO- } \\
\text { LATE } \\
\text { FARMÁ- } \\
\text { CIA } \\
\text { ÔNIBUS }\end{array}$ & $\begin{array}{l}\text { BOBAGEM } \\
\text { SACRIFÍ- } \\
\text { CIO }\end{array}$ & $\begin{array}{l}\text { COM- } \\
\text { PRAR }\end{array}$ & $\begin{array}{c}\text { AGUENTAR/ } \\
\text { APERTAD@ } \\
\text { PROBLEMA }^{14} \\
\text { SOCIEDADE }\end{array}$ & $\begin{array}{c}\text { AJUDAR } \\
\text { ERRAD@ } \\
\text { METRÔ } \\
\text { VIDRO }\end{array}$ & \\
\hline \multicolumn{3}{|c|}{19} & 4 & 2 & 1 & \multicolumn{2}{|l|}{7} & 33 \\
\hline
\end{tabular}

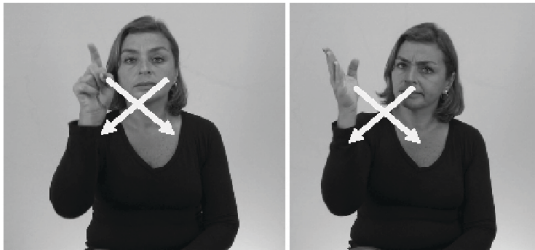

Figura 3: CANCELAR

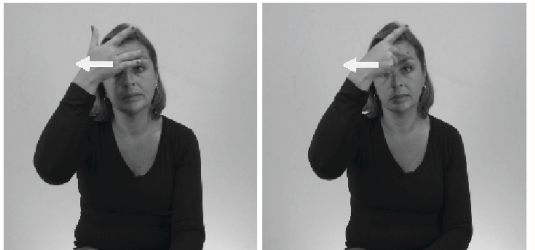

Figura 4: PESSOA
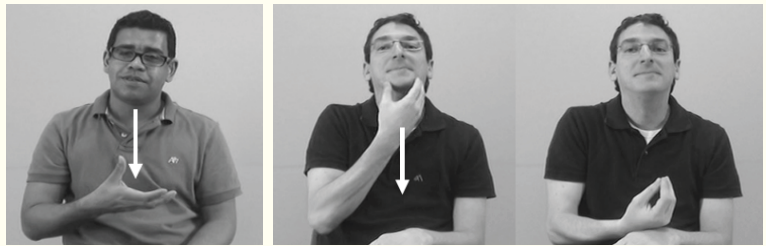

Figura 5: NATAL

13. A notação por glosas dos sinais da libras citados neste trabalho segue as convenções citadas em Felipe de Souza (1998). Notam-se os sinais por meio de uma palavra, grafada em letras maiúsculas, que corresponde a uma tradução possível do sinal para o português. Nos casos em que a tradução resulta em mais de uma palavra, utiliza-se o hífen como forma de indicar que elas representam conjuntamente um sinal. Emprega-se o arroba (@) no lugar de desinências de gênero de palavras do português, em virtude de os sinais não apresentarem marcas do mesmo tipo. Representam-se verbos sempre por meio de sua forma infinitiva no português.

14. O sinal PROBLEMA também apresenta uma variante em que a mão dominante exibe a mesma configuração da mão não-dominante. Este e o outro caso serão discutidos na seção 5.1 . 


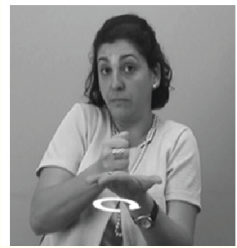

Figura 6: FARMÁCIA

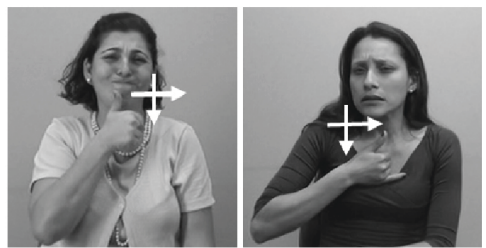

Figura 7: SACRIFÍCIO
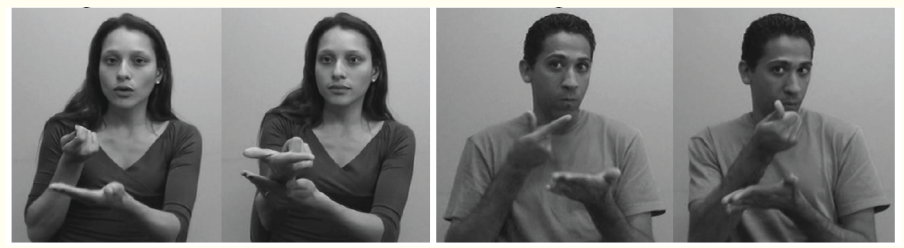

Figura 8: COMPRAR

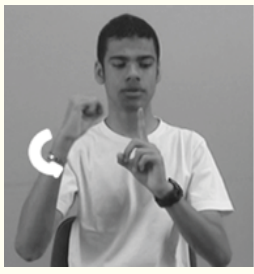

Figura 9: SOCIEDADE

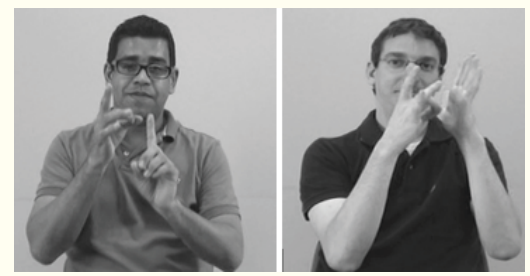

Figura 10: TEXTO

Além desses, usamos como estímulos outros 27 sinais que observamos variar na realização de sua localização, de seu movimento, de sua orientação, de sua face, de seu número de mãos, ou de suas marcações não-manuais. Esses sinais são listados no Quadro 2 e exemplificados nas Figuras 11-17.

Quadro 2: Estímulos usados para a eliciação de variação nos parâmetros localização, movimento, orientação, número de mãos e marcações não-manuais

\begin{tabular}{|c|c|c|c|c|c|c|c|}
\hline \multicolumn{2}{|c|}{$\begin{array}{c}\text { (1) } \\
\text { Localização }\end{array}$} & \multicolumn{2}{|c|}{$\begin{array}{c}\text { (2) } \\
\text { Movimento }\end{array}$} & \multirow[t]{2}{*}{$\stackrel{(3)}{\text { Orientação }}$} & \multirow[t]{2}{*}{$\begin{array}{c}\text { (4) } \\
\text { Número de mãos }\end{array}$} & \multirow{2}{*}{$\begin{array}{l}\text { (5) } \\
\text { Marcações não- } \\
\text { manuais }\end{array}$} & \multirow[t]{2}{*}{ Tota } \\
\hline $\begin{array}{c}\text { (a) } \\
\text { Lateral/ } \\
\text { Centro }\end{array}$ & $\begin{array}{c}\text { (b) } \\
\text { Localização } \\
\text { mais baixa }\end{array}$ & $\begin{array}{c}\text { (a) } \\
\text { Sem/Com }\end{array}$ & $\begin{array}{c}\text { (b) } \\
\text { Diferentes tipos }\end{array}$ & & & & \\
\hline $\begin{array}{c}\text { ALÍVIO } \\
\text { LEMBRAR } \\
\text { OURO }\end{array}$ & $\begin{array}{l}\text { NÃO-SABER } \\
\text { ENTENDER }\end{array}$ & $\begin{array}{l}\text { GOSTAR } \\
\text { OITO }\end{array}$ & $\begin{array}{c}\text { GORD@ } \\
\text { SHOPPING } \\
\text { TEMA/ } \\
\text { TÍTULO } \\
\text { TRABALHAR } \\
\text { LÍNGUA-DE- } \\
\text { SINAIS }\end{array}$ & $\begin{array}{c}\text { LETRA-A } \\
\text { PROIBID@ } \\
\text { PRÓPRI@ }\end{array}$ & $\begin{array}{c}\text { ACEITAR } \\
\text { CAFÉ } \\
\text { CARRINHO } \\
\text { MADRUGADA } \\
\text { NORMAL } \\
\text { PIPA } \\
\text { PRECISAR } \\
\text { PORTO-ALEGRE } \\
\text { QUERER } \\
\text { TARDE }\end{array}$ & $\begin{array}{l}\text { ESTADOS- } \\
\text { UNIDOS } \\
\text { ROUBAR }\end{array}$ & \\
\hline \multicolumn{2}{|c|}{5} & \multicolumn{2}{|r|}{7} & 3 & 10 & 2 & 27 \\
\hline
\end{tabular}




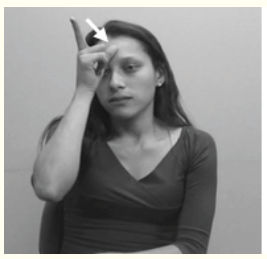

Figura 11: ALÍVIO

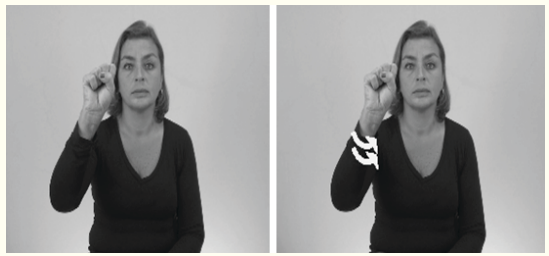

Figura 13: OITO

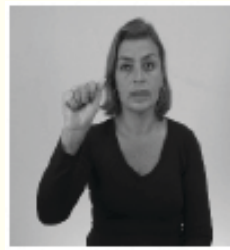

Figura 15: LETRA-A

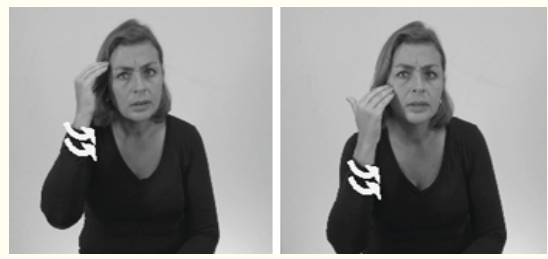

Figura 12: ENTENDER
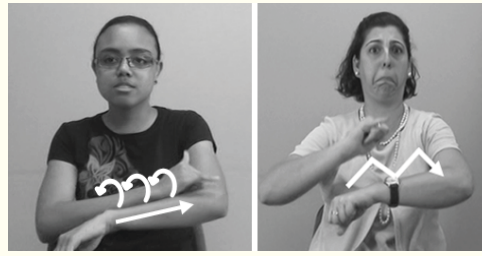

Figura 14:GORD@
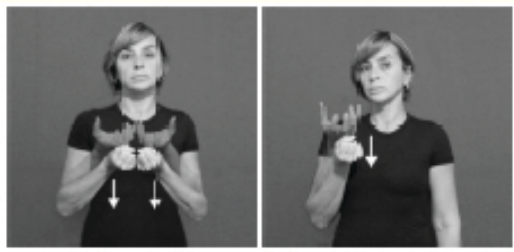

Figura 16: ACEITAR
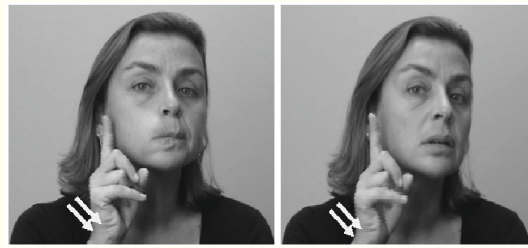

Figura 17: ESTADOS-UNIDOS

Identificamos para os sinais que apresentam variação em sua localização dois padrões diferentes. Um deles consiste na possibilidade de se produzirem certos sinais no centro ou na extremidade ipsilateral do rosto (cf. ALÍVIO, Figura 11) ${ }^{15}$. Já o segundo padrão consiste em reali-

15. Por não dispormos de dados diacrônicos, não é possível determinar se a variação em discussão pode ser descrita como resultante de um processo de centralização (realização de localizações nas extremidades do corpo em regiões centrais) ou de lateralização, o oposto da centralização. 
zar certos sinais em localizações mais baixas em relação à localização em que tipicamente são produzidos (cf. ENTENDER, Figura 12).

Também identificamos, para os sinais que apresentam variação no parâmetro movimento identificamos, dois diferentes padrões. Um deles consiste na possibilidade de realizar certos sinais sem ou com movimento (cf. OITO, Figura 13) e o outro em se poder articular um mesmo sinal com pelo menos dois tipos diferentes de movimento (cf. GORD@, Figura 14). Finalmente, para os demais parâmetros articulatórios, orientação, número de mãos e marcações não-manuais, os padrões de variação observados, e esperados em nossos dados, consistiam, respectivamente, em apresentar a palma orientada para o lado ou para frente, ser realizado com uma ou duas mãos e exibir ou não alguma atividade da face (cf. LETRA-A, Figura 15; ACEITAR, Figura 16, e ESTADOS-UNIDOS, Figura 17).

O uso desses sinais como estímulos no experimento aqui reportado objetivou (1) verificar se as variações que atestamos em sinalizações espontâneas também se manifestam nas produções dos sujeitos deste estudo e, em caso afirmativo, (2) quantificar essa manifestação nas produções desse conjunto de sujeitos.

\subsection{Procedimentos}

Os procedimentos aqui adotados se basearam nos empregados por Israel e Sandler (2009). Apresentamos os estímulos na tela de um laptop Philips modelo Core 2 Duo T6400 13,3" por meio da ferramenta Power Point da Microsoft em seu modo de exibição automático. O intervalo entre cada estímulo foi de 4 segundos e cada sessão do experimento durou em média um pouco mais que 15 minutos.

Para a maioria dos estímulos deste experimento, utilizamos um slide contendo uma glosa em português, correspondente ao significado do sinal a ser eliciado, bem como uma imagem ilustrando ou sugerindo o mesmo (Figura 18a). Nos casos em que o uso de uma imagem não nos pareceu possível (apenas quatro, a saber, ACEITAR, BOBAGEM, NORMAL e TAMBÉM), a eliciação se deu apenas por meio da glosa (Figura 18b). 


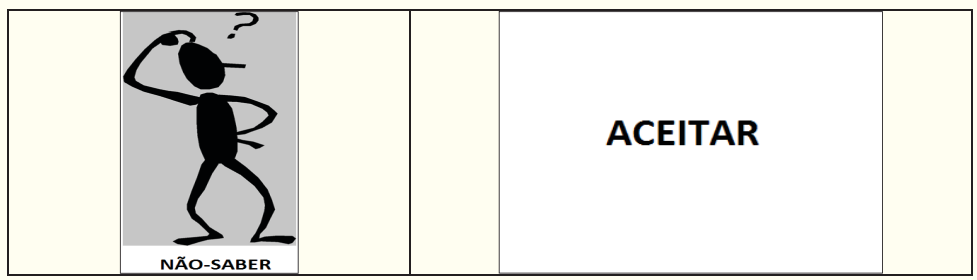

(a)

(b)

Figura 18: Slides empregados para eliciar os sinais NÃO-SABER (a) e ACEITAR (b).

Para nos certificarmos de que as glosas eliciariam os sinais esperados, antes do início do experimento, solicitamos a todos os sujeitos que lessem e sinalizassem uma lista contendo todas elas. Quando a glosa eliciou um sinal diferente do esperado, solicitamos aos sujeitos que pensassem em outro sinal que também pudesse receber a mesma glosa em português. Ao conseguirem produzir o sinal que esperávamos (isso sempre aconteceu, apesar de alguns sujeitos terem levado mais tempo do que outros), instruímos os sujeitos a empregar esse sinal durante a realização do experimento sempre que vissem a glosa em questão. Como se verá na seção resultados, no entanto, mesmo assim, em alguns casos, alguns sinalizadores empregaram durante o experimento um sinal diferente.

Todos os sujeitos foram instruídos em libras pelo primeiro autor deste trabalho, que é sinalizador fluente. Explicamos a eles que, como parte da tarefa experimental, deveriam olhar para cada slide na tela do laptop, ler a glosa, e examinar, quando houvesse, a imagem correspondente. Em seguida, eles deveriam olhar para nosso assistente surdo, sentado ao lado de uma câmera Samsung modelo Hyper DIS $65 \mathrm{x}$ intelli-zoom, e produzir o sinal dirigindo-se para ele.

Cada um dos 60 estímulos foi apresentado três vezes em ordem aleatória para cada um dos 12 sujeitos em sessões separadas, resultando em um total de 2.160 produções $(60 \times 3 \times 12)$. Os sujeitos só foram informados do objetivo do estudo após o fim de sua participação. Por terem realizado o experimento em sessões com horários diferentes, estes acabaram impedidos de conversar entre si sobre os objetivos da pesquisa, bem como sobre a tarefa experimental ${ }^{16}$.

16. Antes de cada sessão, foi apresentado a cada um dos participantes um vídeo contendo a tradução para a libras do termo de consentimento livre e esclarecido no qual, entre outras coisas, se pede autorização para o uso de sua imagem na publicação de artigos científicos. 


\subsection{Análise}

Para a análise dos dados, utilizamos o software livre Elan ${ }^{17}$ (Eudico Language Annotator) desenvolvido pelo Max Plank Institute. Esse software nos permitiu segmentar os vídeos referentes à participação de cada sujeito, bem como fazer anotações neles. As análises estatísticas foram realizadas com o programa, também livre, $\mathrm{R}^{18}$.

\section{Resultados}

A análise de nossos dados revelou que, além dos parâmetros de variação considerados na fase de elaboração do experimento aqui descrito, os sinais que eliciamos variaram também em outros aspectos. Atestamos, para alguns sinais, variantes realizadas (1) com e sem contato (e.g. METRÔ, SUPERMERCADO), (2) com o movimento realizado pelo pulso ou pelo antebraço (distalização) (e.g. SHOPPING), (3) com ou sem repetição do movimento (e.g. QUERER), (4) com ou sem a oralização total ou parcial da palavra correspondente em português (e.g. FUSCA) e (5) com ou sem movimento na mão nãodominante (e.g. DESCOBRIR, ELEVADOR). Além disso, atestamos também a produção de alguns dos sinais eliciados como parte de um composto, e não como sinal simples, tal como esperado (e.g. CARRINHO, DESCOBRIR, FARMÁCIA, FUSCA, LÍNGUA-DE-SINAIS, NATAL, SALÁRIO e TEXTO).

Optamos, neste trabalho, por focar na variação dos parâmetros originalmente considerados e deixar os não previstos para trabalhos futuros, dado que aqueles casos ilustram suficientemente não apenas a grande variabilidade existente entre os sinalizadores, mas também a complexidade da variação na realização dos sinais da libras.

Os resultados discutidos nas sub-seções 5.1 a 5.5 referem-se à variação inter-sujeito, quantificada através do número de participantes que empregaram cada uma das variantes aqui discutidas. Em alguns casos, o total de sujeitos não atingiu 12 ou porque alguns sujeitos não 
produziram o sinal esperado (cf. ALT@, FARMÁCIA, GOSTAR e NÃO-AGUENTAR), ou porque produziram variantes que pertenciam a outra categoria de variação (cf. ALT@, DESCOBRIR, FUSCA, LETRA-X, MADRUGADA, METRÔ e SUPERMERCADO), ou ainda porque produziram as duas variantes em sequência (cf. SUPERMERCADO, VIDRO). Nos casos em que entre as três produções de um mesmo sujeito foram atestadas mais de uma variante - variação intra-sujeito -, considerou-se, para efeitos de quantificação por sujeito, a variante empregada mais vezes por este.

\subsection{Variação na configuração de mão}

Entre os sinais que podem ser realizados com diferentes configurações nativas, observamos, como mostra a Tabela 1, que a maior parte desses casos apresentou as duas configurações de mão esperadas, com predominância de uma delas. Os únicos sinais que não seguiram exatamente esse padrão foram AVIÃO, CANCELAR e TAMBÉM, dado que para o sinal AVIÃO só obtivemos ocorrências de uma das configurações esperadas, para o sinal CANCELAR obtivemos, além das duas, uma terceira variante não esperada (todos os dedos abertos, inclusive o polegar, abertos e se contactando pelas laterais), e para TAMBÉM as variantes ocorreram com a mesma frequência.

Tabela 1: Frequência das variantes de sinais que podem ser realizados com diferentes configurações de mão nativas por número de sujeitos

\begin{tabular}{|c|c|c|c|c|c|c|}
\hline Sinal & $\begin{array}{l}\text { Configuração de } \\
\text { mão }\end{array}$ & $\begin{array}{l}\text { Número de } \\
\text { sujeitos }\end{array}$ & $\begin{array}{c}\text { Configuração } \\
\text { de mão }\end{array}$ & $\begin{array}{l}\text { Número de } \\
\text { sujeitos }\end{array}$ & $\begin{array}{c}\text { Configuração } \\
\text { de mão }\end{array}$ & $\begin{array}{c}\text { Número } \\
\text { de sujeitos }\end{array}$ \\
\hline AVIÃo & & 12 & & 0 & - & - \\
\hline PREOCUPAD@ & & 11 & a) & 1 & - & - \\
\hline SILÊNCIO & & 11 & ? & 1 & - & - \\
\hline VERDADE & & 11 & $w$ & 1 & - & - \\
\hline LETRA-X & & 9 & & 1 & - & - \\
\hline ALT@ & & 9 & 51 & 3 & - & - \\
\hline CANCELAR & & 9 & & 2 & $\Rightarrow$ & 1 \\
\hline SUPERMERCADO & & 7 & $\{?$ & 5 & - & - \\
\hline SALÁRIO & है & 7 & 成 & 5 & - & - \\
\hline TAMBÉM & ही & 6 & की & 6 & - & - \\
\hline
\end{tabular}


A maior ocorrência de algumas configurações, semelhantemente ao que demonstra Ann (2005) em um trabalho sobre a frequência de configurações de mão na língua de sinais taiwanesa, parece ser motivada pela menor complexidade articulatória destas em relação à variante concorrente. No caso de AVIÃO, PREOCUPAD@, SILÊNCIO e LETRA-X, por exemplo, as configurações mais frequentes envolvem menos dedos do que suas respectivas concorrentes menos frequentes ${ }^{19}$. Já no caso de ALT@, apesar de o número de dedos das duas variantes ser o mesmo, a configuração mais frequente não exibe a flexão das juntas medial e distal presente na variante com configuração menos frequente.

Já a predominância de uma das variantes dos sinais VERDADE, SUPERMERCADO e SALÁRIO, no entanto, deve envolver outro(s) fator(es), já que a variante mais frequente não parece ser articulatoriamente menos complexa. Além desses, oito outros sinais previstos para variar em outros aspectos articulatórios apresentaram variação em sua configuração de mão, a saber, BOBAGEM, DESCOBRIR, ELEVADOR (mão dominante), ENTENDER, EMPRESA, NATAL e NÃO-AGUENTAR/APERTAD@ (Tabela 2). Semelhantemente à maioria dos casos na categoria em questão, tais sinais apresentaram uma variante mais frequente que as outras. Entretanto, tal como no caso de VERDADE, SUPERMERCADO e SALÁRIO, a maior frequência de uma das variantes não parece se explicar por esta ser articulatoriamente menos complexa que as demais, com exceção de ENTENDER.

19. Um contra-exemplo a isso é o sinal TAMBÉM cujas variantes apresentaram frequências muito próximas, mesmo que uma delas seja articulatoriamente menos complexa do que a outra. 
Tabela 2: Frequência, por número de sujeitos, das variantes de sinais que variaram em sua configuração apesar de ser esperado que variassem em outros parâmetros

\begin{tabular}{|c|c|c|c|c|c|c|}
\hline Sinal & $\begin{array}{c}\text { Configuração de } \\
\text { mão }\end{array}$ & $\begin{array}{l}\text { Número de } \\
\text { sujeitos }\end{array}$ & $\begin{array}{l}\text { Configuração de } \\
\text { mão }\end{array}$ & $\begin{array}{c}\text { Número de } \\
\text { sujeitos }\end{array}$ & $\begin{array}{c}\text { Configuração de } \\
\text { mão }\end{array}$ & $\begin{array}{l}\text { Quantidade } \\
\text { de sujeitos }\end{array}$ \\
\hline $\begin{array}{c}\text { NÁO- } \\
\text { AGUENTAR }\end{array}$ & $\begin{array}{l}\mathrm{F} \text { (polegar em } \\
\text { contato com a } \\
\text { lateral do } \\
\text { indicador, } \\
\text { dobrado na junta } \\
\text { proximal, demais } \\
\text { dedos abertos e } \\
\text { espalmados) }\end{array}$ & 11 & & 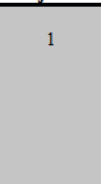 & & \\
\hline EMPRESA & 9 & 9 & & 2 & - & - \\
\hline ELEVADOR & & 7 & & 2 & dी & 2 \\
\hline ENTENDER & $\hat{E}$ & 7 & & 5 & - & - \\
\hline BOBAGEM & & 6 & & 2 & - & - \\
\hline DESCOBRIR & हो & 6 & & 3 & & \\
\hline NATAL & है? & 5 & & 3 & mais aberto & 2 \\
\hline ÔNIBUS & $9 ?$ & 4 & 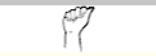 & 1 & - & - \\
\hline
\end{tabular}

Os sinais cuja configuração da mão varia entre uma configuração nativa e outra inicializada ${ }^{20}$, por sua vez, tiveram, em sua maioria, a variante com a configuração de mão nativa como a mais frequente, conforme mostra a Figura 19. Os únicos sinais que não seguiram esse padrão foram PESSOA $^{21}$ e FUSCA.

20. Não encontramos na literatura sobre a ASL qualquer menção a casos como este. Curiosamente, entretanto, há sinais nessa língua, como MONEY (dinheiro) e ECONOMICS (economia), em que se observa o mesmo tipo de alternância: o primeiro realizado com uma configuração de mão nativa e o segundo com uma configuração inicializada. Por terem significados distintos, apesar de relacionados, esses casos não são variantes de um mesmo sinal, mas sim sinais diferentes. De acordo com Brentari (2001), sinais como ECONOMICS (economia) se originaram a partir de um processo de derivação lexical bastante recorrente na criação de termos técnicos na ASL que consiste, justamente, em alterar a configuração de mão nativa de um dado sinal por uma configuração de mão que corresponda no alfabeto manual à inicial de uma palavra do inglês com significado relacionado, mas, em geral, mais específico que o sinal. Entre os exemplos que a autora cita estão os sinais BIOLOGY (biologia), CHEMSTRY (química) e EXPERIMENT (experimento), que constituem versões inicializadas do sinal SCIENCE (ciência).

21. Seguindo Xavier (2011), reiteramos que, por falta dados diacrônicos, não é possível afirmar com certeza se a configuração aqui considerada como não-nativa no sinal PESSOA é de fato nativa ou se representa uma modificação da configuração inicializada. 


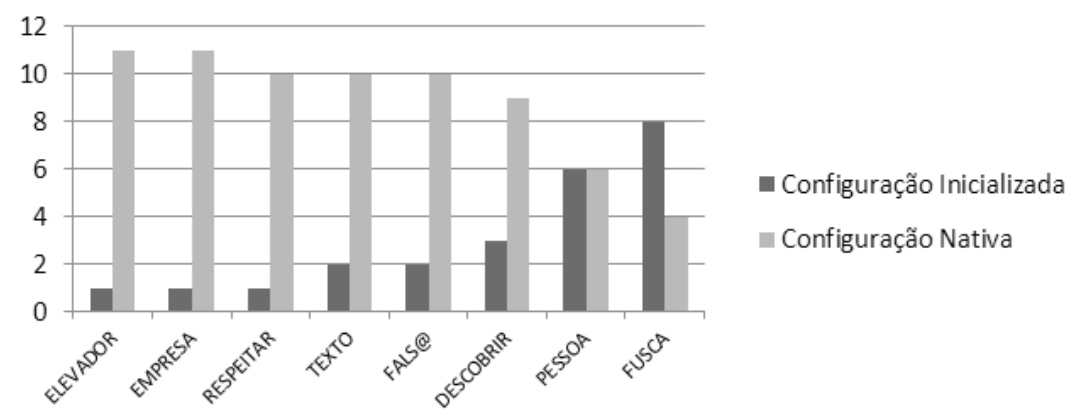

Figura 19: Frequência das variantes de sinais que podem apresentar configuração de mão inicializada ou nativa por número de sujeitos

Os resultados obtidos para a maior parte dos casos nessa subcategoria parecem ir ao encontro da avaliação negativa do uso de sinais inicializados. Para muitos surdos usuários da libras, esses sinais refletem influência do português em sua língua e, por essa razão, devem ser evitados.

Em relação à subcategoria de sinais que variam no número de configurações de mão (uma ou duas), além do único sinal previsto para apresentar tal variação, NATAL, atestamos três outros em nossos dados: LETRA-X, SHOPPING e SOCIEDADE. Conforme se pode ver na Figura 3, predominam as variantes produzidas com apenas uma configuração, o que sugere, mais uma vez, um favorecimento das formas articulatoriamente menos complexas.

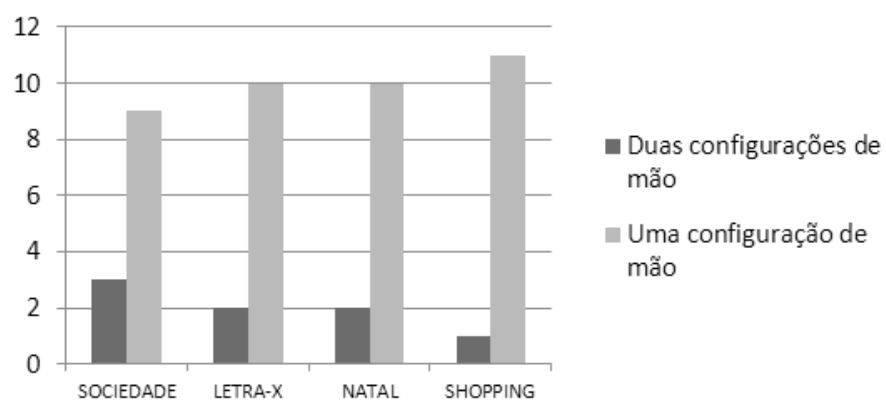

Figura 20: Frequência das variantes de sinais que podem apresentar uma ou duas configurações de mão por número de sujeitos 
No que diz respeito à distenção ou não do polegar, nossos resultados sugerem uma dependência lexical, uma vez que tal processo não ocorreu uniformemente em nossos dados. Como mostra o gráfico abaixo, há casos em que apenas uma das variantes foi atestada (BRINCAR e CHOCOLATE) e há casos em que uma das variantes predominou (ÔNIBUS, FARMÁCIA e NORMAL).

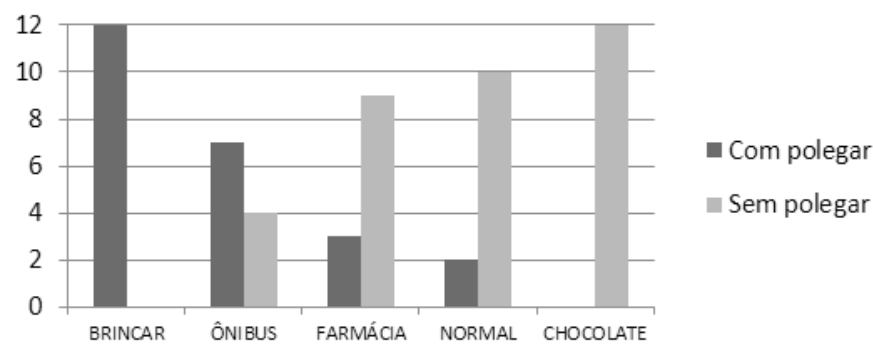

Figura 21: Frequência das variantes de sinais que podem apresentar ou não distenção do polegar por número de sujeitos

Uma situação diferente foi observada nos casos de variação na distenção do dedo mínimo, já que predominaram as variantes em que esse dedo não aparece distendido (Figura 5).

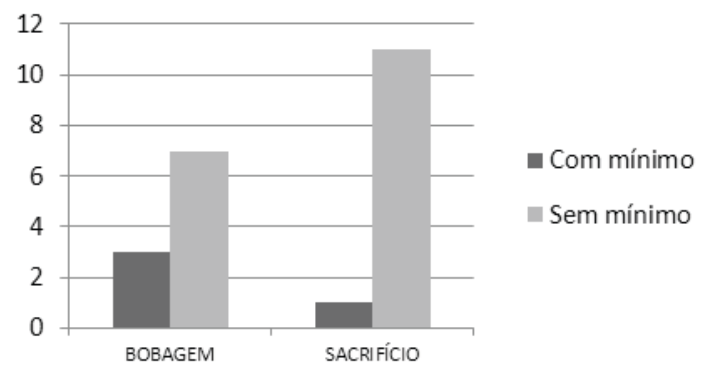

Figura 22: Frequência das variantes de sinais que podem apresentar ou não distensão do dedo mínimo por número de sujeitos

Em Xavier (2013), a variante de SACRIFÍCIO com o dedo mínimo distendido só apareceu sistematicamente nas realizações de dois 
sujeitos quando estes produziram a forma intensificada desse sinal. $\mathrm{O}$ uso dessa variante em resposta a um estímulo que objetivava eliciar a forma neutra dos sinais e não a intensificada, bem como a própria variação interna do único participante que a produziu, sugere que a oposição observada por Xavier não deve ser realizada por todos os sinalizadores da libras.

Em relação ao único caso previsto para variar na ordem de realização de suas duas configurações de mão (metátese), COMPRAR, observamos a predominância da variante em que a mão dominante muda de L (indicador e polegar distendidos, demais fechados) para A (polegar em contato com a lateral do indicador, demais dobrados nas juntas e em contato com a palma da mão pelas pontas), em relação à variante em que a mesma muda de A para L. Diferentemente de algumas outras subcategorias de variação, nenhum outro sinal, entre os selecionados para este estudo, apresentou o mesmo tipo de variação.

Por fim, os casos de variação em sinais assimétricos, ou seja, realizados com as mãos diferentemente configuradas, apresentaram os dois padrões de variação esperados. Entre aqueles que podem exibir ou não ambas as mãos com a mesma configuração, já incluindo ALT@, PIPA e TEXTO, originalmente não previstos para apresentar esse tipo de variação, observamos três comportamentos diferentes. Como motra a Figura 6, há sinais, como METRÔ, em que predomina a variante em que a mão não-dominate assume a mesma configuração que a dominante, sinais como NÃO-AGUENTAR/APERTAD@, SOCIEDADE e TEXTO em que predomina a variante com ambas as mãos configuradas diferentemente e sinais como PROBLEMA em que predomina a variante em que a mão dominante assume a configuração da mão não-dominante. ALT@ e PIPA só ocorreram duas vezes com duas mãos em nossos dados, o que nos impediu de observar qual variante é mais ou menos frequente. 


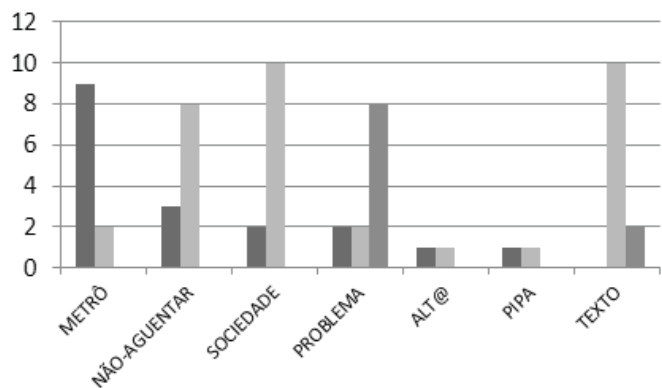

• Configuração igual à da mão dominante

- Configuração diferente da mão dominante

n Configuração igual à da mão não-dominante

Figura 23: Frequência das variantes de sinais que podem apresentar na mão não-dominante configuração idêntica ou diferente da mão dominante por número de sujeitos

Os casos em que as duas mãos exibem a mesma configuração podem ser analisados como casos de assimilação. Esse processo já foi atestado na ASL por Frishberg (1975) em um estudo diacrônico que mostrou uma tendência de sinais assimétricos se tornarem simétricos, ou seja, apresentarem a mesma configuração em ambas as mãos. A autora reporta que esse processo pode acontecer de dois modos diferentes na ASL: (1) a mão não-dominante assimila a configuração da mão dominante ou (2), o contrário, a mão dominante assimila a configuração da mão não-dominante.

Como indica o gráfico em 6 , ambos os modos foram atestados nos sinais da libras em análise. Em METRÔ, NÃO-AGUENTAR/APERTAD@, SOCIEDADE, ALT@ e PIPA a assimilação ocorre da mão dominante para a mão não-dominante. Já em TEXTO, a assimilação acontece na direção contrária, da mão não-dominante para a dominante. Interessantemente, o sinal PROBLEMA (Figura 24a), apresentou as duas direções para o processo assimilatório, já que ocorreu em nossos dados tanto com a mão não-dominante com a mesma configuração da dominante, caso no qual ambas aparecem configuradas em 1 (indicador distendido, demais fechados) (Figura 24b), quanto com a mão dominante exibindo a mesma configuração que a não-dominante, caso no qual as duas mãos aparecem configuradas em L (indicador e polegar distendidos, demais fechados) (Figura 24c). 


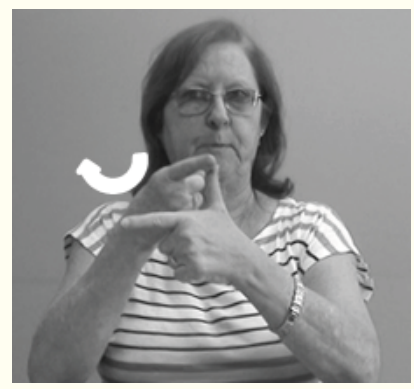

(a)

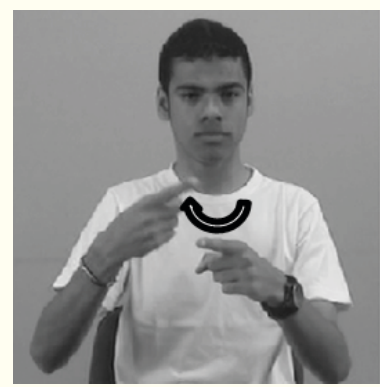

(b)

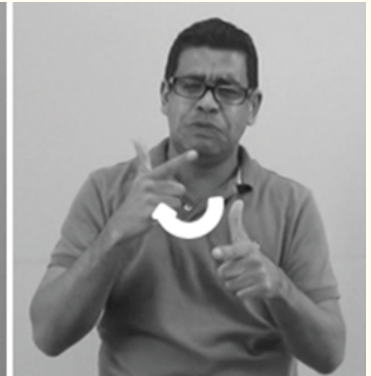

(c)

Figura 24: PROBLEMA

Já em relação aos sinais que seguem o segundo padrão de variação, observamos a predominância de uma das variantes em relação à(s) outra(s), tal como em outros casos já discutidos. Observamos também que entre esses casos predomina uma configuração de mão, aqui designada como "B relaxado" ${ }^{22}$, que exibe os dedos nem tão unidos pelas laterais nem tão separados (Tabela 3).

22. Estamos desigando a referida configuração nominalmente, em razão de as fontes do handshape2002, aqui empregadas e disponíveis em http://lifeprint.com/as1101/fingerspelling/gallaudet/GALLAUDET.ttf, não incluírem um símbolo apropriado para ela. 
Tabela 3: Frequência das variantes de sinais que podem ser produzidos com diferentes configurações na mão não-dominante por número de sujeitos

\begin{tabular}{|c|c|c|c|c|c|c|}
\hline Sinal & $\begin{array}{c}\text { Configuração da } \\
\text { mão não- } \\
\text { dominante } \\
\end{array}$ & $\begin{array}{l}\text { Número de } \\
\text { sujeitos }\end{array}$ & $\begin{array}{l}\text { Configuração } \\
\text { da mão não- } \\
\text { dominante }\end{array}$ & $\begin{array}{l}\text { Número de } \\
\text { sujeitos }\end{array}$ & $\begin{array}{c}\text { Configuração } \\
\text { da mão não- } \\
\text { dominante }\end{array}$ & $\begin{array}{c}\begin{array}{c}\text { Número } \\
\text { de }\end{array} \\
\text { sujeitos }\end{array}$ \\
\hline ERRAD@ & B relaxado & 12 & $9 ?$ & 0 & - & \\
\hline VIDRO & $B$ relaxado & 9 & (3) & 2 & - & \\
\hline FUSCA & $B$ relaxado & 9 & 11 & 2 & - & \\
\hline AJUDAR & R & 8 & \{\} & 4 & - & \\
\hline MADRUGADA & B relaxado & 2 & (5) & 4 & की & 2 \\
\hline METRÔ & $?$ & 1 & 81 & 1 & - & \\
\hline DESCOBRIR & $?$ & 1 & & & - & \\
\hline
\end{tabular}

\subsection{Variação na localização}

Dentre os sinais previstos para variar em sua localização por poderem ser realizados em uma região mais central ou lateral da face, observamos, além dessas duas localizações, uma localização intermediária. A frequência da cada uma das variantes variou de sinal para sinal (Figura 25).

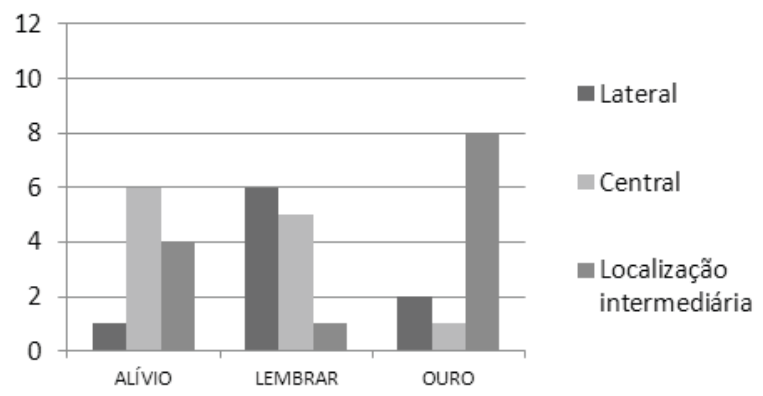

Figura 25: Frequência das variantes de sinais que podem variar sua localização: centralização/lateralização

Já para os sinais cuja localização pode variar entre uma localização mais alta (em nosso caso, lateral da testa) e outra(s) mais baixa(s) (têmpora, bochecha, etc.) (cf. ENTENDER e NÃO-SABER), atestamos apenas as variantes produzidas em pontos mais altos. Isso pode ter 
acontecido em virtude de esse fenômeno ser mais comum em sinalização informal (LIDDELL; JOHNSON, 1989) e corrente.

Além desses sinais, cinco outros, previstos para variar em outros aspectos articulatórios, também variaram em sua localização. Como mostra a Tabela 4 a seguir, apesar de apresentarem, em alguns casos, até três variantes, esses sinais foram mais frequentemente produzidos em uma delas.

Tabela 4: Frequência das variantes de sinais que variaram em sua localização apesar de originalmente não previstos para variar nesse parâmetro

\begin{tabular}{c|c|c|c|c|c|c} 
Sinal & Localização & $\begin{array}{c}\text { Número } \\
\text { de sujeitos }\end{array}$ & Localização & $\begin{array}{c}\text { Número de } \\
\text { sujeitos }\end{array}$ & Localização & $\begin{array}{c}\text { Número de } \\
\text { sujeitos }\end{array}$ \\
\hline GORD@ & $\begin{array}{c}\text { Do pulso ao } \\
\text { cotovelo }\end{array}$ & 11 & $\begin{array}{c}\text { Do pulso ao } \\
\text { ombro }\end{array}$ & 1 & & \\
FUSCA & $\begin{array}{c}\text { Dorso da } \\
\text { mão não- } \\
\text { dominante }\end{array}$ & 10 & Antebraço & 1 & $\begin{array}{c}\text { Espaço } \\
\text { neutro }\end{array}$ & 1 \\
AVIÃO & $\begin{array}{c}\text { Do lado } \\
\text { direito para o } \\
\text { esquerdo }\end{array}$ & 9 & $\begin{array}{c}\text { Do lado } \\
\text { direirto para } \\
\text { a frente }\end{array}$ & 2 & $\begin{array}{c}\text { direito para } \\
\text { a diagonal } \\
\text { esquerda }\end{array}$ & 1 \\
QUERER & $\begin{array}{c}\text { Para trás (e } \\
\text { para frente) } \\
\text { Para trás }\end{array}$ & 8 & $\begin{array}{c}\text { Para cima e } \\
\text { para baixo }\end{array}$ & 2 & $\begin{array}{c}\text { Para os } \\
\text { lados }\end{array}$ & 2 \\
\hline LETRA-X & $\begin{array}{c}\text { Para baixo } \\
\text { Pados }\end{array}$ & 5 & &
\end{tabular}

\subsection{Variação no movimento}

Os dois sinais que esperávamos variar em relação à presença ou ausência de movimento apresentaram comportamentos diferentes. Enquanto para GOSTAR a variante mais frequente foi aquela com movimento, para OITO, a variante mais frequente foi exatamente aquela que não exibe movimento (Figura 26). 


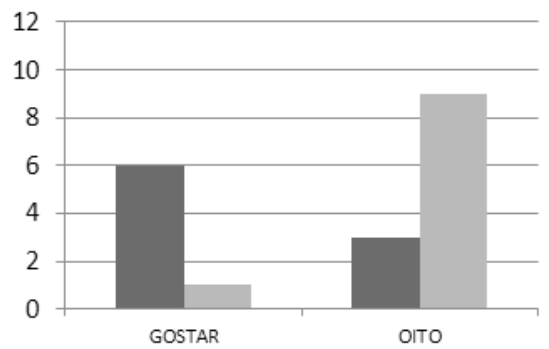

- Com movimento

- Sem movimento

Figura 26: Frequência das variantes de sinais que podem ser produzidos com ou sem movimento por número de sujeitos

A maior frequência da variante de GOSTAR com movimento pode estar relacionada a uma certa "preferência", por parte dos sinalizadores da libras, por sinais com movimento, em detrimento de sinais realizados com a mão parada. Essa "preferência" deve advir do fato de sinais sem movimento serem menos frequentes na língua. De acordo com Xavier (2006), dos 2.269 sinais da libras que estudou, apenas 213 não apresentam movimento. O sinal OITO, em contraste, deve ter tido como variante mais frequente aquela que não apresenta movimento, em razão de a variante com movimento ser altamente estigmatizada entre alguns surdos sinalizadores da cidade de São Paulo. Segundo Xavier (2011), diz-se entre estes que a realização do sinal OITO com o girar do pulso foi introduzida por ouvintes (provavelmente professores de surdos ou fonoaudiólogos), a fim de diferenciá-lo do sinal homônimo LETRA-S. Por essa razão, sobretudo entre surdos mais militantes, o uso dessa variante é altamente estigmatizada, tendo em vista a susposta origem associada aos ouvintes.

Já em relação aos sinais que esperávamos apresentar diferentes formas de movimento, observamos, assim como no caso dos sinais que variam em sua configuração de mão, (1) a ocorrência de variantes não previstas, (2) a predominância de uma das variantes e (3) a inclusão nesta subcategoria de sinais que, apesar de não previstos para variar em seu movimento, exibiram também variação nesse parâmetro (cf. ALT@, CARRINHO e EMPRESA) (Tabela 5). 
Tabela 5: Frequência das variantes dos sinais que podem ser realizados com diferentes formas de movimento por número de sujeitos

\begin{tabular}{|c|c|c|c|c|c|c|}
\hline Sinal & $\begin{array}{l}\text { Tipo de movi- } \\
\text { mento }\end{array}$ & $\begin{array}{l}\text { Número de } \\
\text { sujeitos }\end{array}$ & $\begin{array}{l}\text { Tipo de movi- } \\
\text { mento }\end{array}$ & $\begin{array}{c}\text { Número } \\
\text { de sujeitos }\end{array}$ & $\begin{array}{c}\text { Tipo de } \\
\text { movimento }\end{array}$ & $\begin{array}{l}\text { Número de } \\
\text { sujeitos }\end{array}$ \\
\hline EMPRESA & $\begin{array}{c}\text { Reto sem girar os } \\
\text { pulsos }\end{array}$ & 11 & $\begin{array}{l}\text { Reto girando os } \\
\text { pulsos }\end{array}$ & 1 & & \\
\hline AVIÃO & Reto & 11 & $\begin{array}{c}\text { Em arco para } \\
\text { o lado }\end{array}$ & 1 & & \\
\hline TÍTULO & $\begin{array}{l}\text { Mov. de fechar } \\
\text { dedos }\end{array}$ & 10 & $\begin{array}{l}\text { Movimento de } \\
\text { fechar os dedos } \\
\text { com abaixamen- } \\
\text { to dos braços }\end{array}$ & 1 & $\begin{array}{c}\text { Balançar } \\
\text { lateralmente } \\
\text { pelos pulsos } \\
\text { para baixo }\end{array}$ & 1 \\
\hline CARRINHO & $\begin{array}{l}\text { Reto com osc. } \\
\text { lateral }\end{array}$ & 9 & $\begin{array}{l}\text { Reto sem osc. } \\
\quad \text { lateral }\end{array}$ & 2 & $\begin{array}{c}\text { Reto com } \\
\text { osc. lateral - } \\
\text { lento }\end{array}$ & 1 \\
\hline GORD@ & Zigue-zague & 8 & $\begin{array}{c}\text { Reto com osc. } \\
\text { laterais }\end{array}$ & 4 & & \\
\hline ALT@ & $\begin{array}{l}\text { Circular para } \\
\text { cima }\end{array}$ & 9 & Só circular & 3 & & \\
\hline TRABALHAR & Reto alternado & 9 & $\begin{array}{l}\text { Circular alter- } \\
\text { nado }\end{array}$ & 2 & $\begin{array}{c}\text { Balançar } \\
\text { simultânea e } \\
\text { lateralmente } \\
\text { pelos pulsos } \\
\text { para baixo }\end{array}$ & 1 \\
\hline $\begin{array}{l}\text { LÍNGUA-DE- } \\
\text { SINAIS }\end{array}$ & $\begin{array}{l}\text { Circular alter- } \\
\text { nado }\end{array}$ & 8 & $\begin{array}{l}\text { Osc. lateral } \\
\text { alternada }\end{array}$ & 4 & & \\
\hline SHOPPING & $\begin{array}{l}\text { Circular para } \\
\text { baixo }\end{array}$ & 6 & $\begin{array}{l}\text { Circular para } \\
\text { cima }\end{array}$ & 5 & $\begin{array}{l}\text { Arqueado } \\
\text { para cima }\end{array}$ & 1 \\
\hline
\end{tabular}

\subsection{Variação na orientação}

Dos três sinais originalmente previstos para variar em sua orientação, dois, PROIBID@ e PRÓPRIO, apresentaram uma variante além das duas já esperadas. Todos os três, no entanto, tal como nos resultados discutidos anteriormente, apresentaram uma variante com maior frequência que a(s) outra(s). Observamos também que a variação na orientação da palma não se restringiu a apenas esses três sinais, o que nos levou a incluir nesta categoria seis outros casos, como mostra a Tabela 6 . 
Tabela 6: Frequência das variantes dos sinais que apresentam diferentes orientações/faces por número de sujeitos

\begin{tabular}{|c|c|c|c|c|c|c|}
\hline Sinal & Orientação & $\begin{array}{c}\text { Número } \\
\text { de sujeitos }\end{array}$ & Orientação & $\begin{array}{c}\text { Número } \\
\text { de sujeitos }\end{array}$ & Orientação & $\begin{array}{l}\text { Número de } \\
\text { sujeitos }\end{array}$ \\
\hline LETRA-A & $\begin{array}{l}\text { Palma para } \\
\text { frente }\end{array}$ & 10 & Palma para o lado & 2 & & \\
\hline TRABALHAR & $\begin{array}{c}\text { Palma para baixo } \\
\text { e indicador para } \\
\text { frente }\end{array}$ & 10 & $\begin{array}{l}\text { Palma para dentro } \\
\text { e indicador do } \\
\text { lado para baixo }\end{array}$ & 1 & $\begin{array}{c}\text { Palma para } \\
\text { diagonal e dedos } \\
\text { para a frente }\end{array}$ & 1 \\
\hline $\begin{array}{l}\text { ELEVADOR } \\
\text { (mão não- } \\
\text { dominante) }\end{array}$ & $\begin{array}{l}\text { Palma para o } \\
\text { lado e dedos } \\
\text { para cima }\end{array}$ & 9 & $\begin{array}{l}\text { Palma para a } \\
\text { frente e dedos } \\
\text { para cima }\end{array}$ & 3 & & \\
\hline EMPRESA & $\begin{array}{c}\text { Palmas para o } \\
\text { lado }\end{array}$ & 8 & $\begin{array}{l}\text { Palmas para } \\
\text { frente }\end{array}$ & 3 & $\begin{array}{l}\text { Palmas para } \\
\text { baixo }\end{array}$ & 1 \\
\hline LETRA-X & $\begin{array}{c}\text { Palma para baixo } \\
\text { e indicador para } \\
\text { o lado }\end{array}$ & 8 & $\begin{array}{c}\text { Palma para o lado } \\
\text { e indicador para } \\
\text { o lado }\end{array}$ & 3 & $\begin{array}{l}\text { Palma para fren- } \\
\text { te e indicador } \\
\text { para frente }\end{array}$ & 1 \\
\hline $\begin{array}{l}\text { PROIBID@ } \\
\text { (mão não- } \\
\text { dominante) }\end{array}$ & $\begin{array}{c}\text { Palma e } \\
\text { indicador para a } \\
\text { diagonal }\end{array}$ & 7 & $\begin{array}{c}\text { Palma para baixo } \\
\text { e indicador para a } \\
\text { diagonal }\end{array}$ & 4 & $\begin{array}{l}\text { Palma orientada } \\
\text { para dentro } \\
\text { e indicador } \\
\text { apontando para } \\
\text { o lado }\end{array}$ & 1 \\
\hline $\begin{array}{c}\text { TARDE } \\
\text { (mão dominante) }\end{array}$ & $\begin{array}{c}\text { Palma para baixo } \\
\text { e dedos para a } \\
\text { frente }\end{array}$ & 7 & $\begin{array}{c}\text { Palma para baixo } \\
\text { e dedos para a } \\
\text { diagonal }\end{array}$ & 3 & $\begin{array}{l}\text { Palma para } \\
\text { baixo e dedos } \\
\text { para o } \\
\text { Lado }\end{array}$ & 2 \\
\hline $\begin{array}{c}\text { TEXTO } \\
\text { (mão não- } \\
\text { dominante) }\end{array}$ & $\begin{array}{l}\text { Palma para o } \\
\text { lado e dedos } \\
\text { para cima }\end{array}$ & 5 & $\begin{array}{l}\text { Palma e dedos } \\
\text { para a diagonal }\end{array}$ & 4 & $\begin{array}{l}\text { Palma para fora } \\
\text { e dedos para } \\
\text { cima }\end{array}$ & 3 \\
\hline $\begin{array}{l}\text { PRÓPRIO } \\
\text { (mão não- } \\
\text { dominante) }\end{array}$ & $\begin{array}{l}\text { Palma para o } \\
\text { lado e dedos } \\
\text { para frente }\end{array}$ & 5 & $\begin{array}{l}\text { Palma para fora e } \\
\text { dedos para cima }\end{array}$ & 5 & $\begin{array}{l}\text { Palma para o } \\
\text { lado e dedos } \\
\text { para cima }\end{array}$ & 2 \\
\hline
\end{tabular}

\subsection{Variação no número de mãos}

Além dos dez sinais previstos para variar em seu número de mãos, quatro outros apresentaram o mesmo tipo de variação, a saber, ALT@, ELEVADOR, FUSCA e ROUBAR. A análise desses 14 sinais revelou que eles não formam um grupo homogêneo. Como mostra o gráfico abaixo, há sinais cuja variante predominante é a de duas mãos, ao passo que há outros cuja variante mais frequente é a de uma mão. 


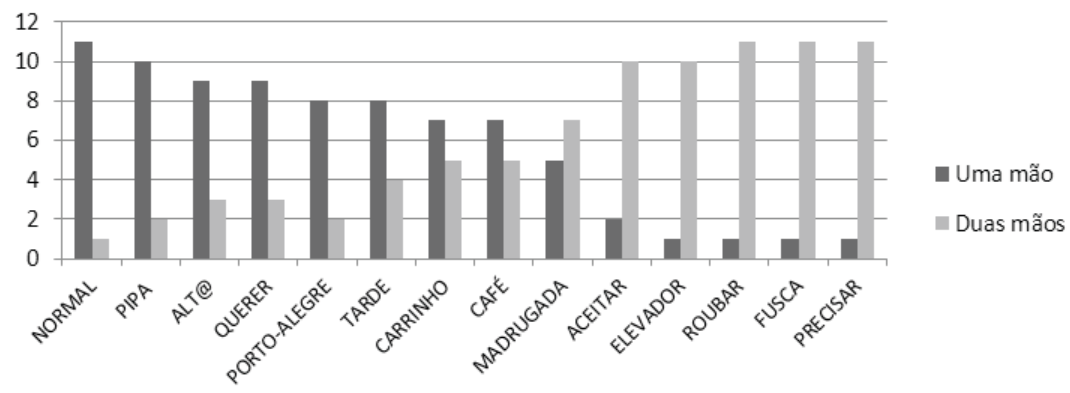

Figura 27: Frequência das variantes dos sinais que podem ser produzidos com uma ou duas mãos por número de sujeitos

Essa heterogeneidade deve se explicar pela presença, na constituição dos sinais em análise, de certas características fonológicas que favorecem ou desfavorecem sua realização com uma ou duas mãos. Para uma discussão mais aprofundada a esse respeito, ver Xavier (2014).

\subsection{Variação nas marcações não-manuais}

Embora esperássemos que apenas os sinais ESTADOS-UNIDOS e ROUBAR apresentassem variação em sua marcação não-manual, quatro outros sinais eliciados em nosso estudo,ALT@, CARRINHO, GORD@e PIPA, também apresentaram variação nesse parâmetro. Em todos esses casos, a variação, tal como prevista, consistiu na realização ou não do componente não-manual do sinal. Como mostra o gráfico a seguir, assim com os casos de variação no número de mãos, o conjunto de sinais em questão não é homogêneo. Há sinais que foram mais frequentemente produzidos sem suas respectivas marcações não-manuais (MNM), enquanto outros foram predominantemente realizados com elas. 


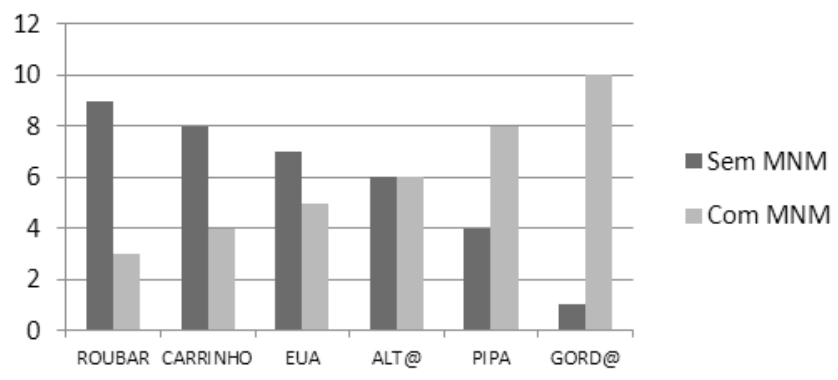

Figura 28: Frequência das variantes de sinais que podem ser produzidos com ou sem marcações não-manuais (MNM)

Interessantemente, esses resultados vão na mesma direção da situação descrita por Johnston e Schembri (2007) na língua de sinais australiana (Auslan). Segundo esses autores, os julgamentos de obrigatoriedade para certas marcações não-manuais que co-ocorrem à produção de alguns sinais da Auslan varia muito entre os usuários dessa língua. Tal fato deve advir da percepção por parte destes de que a marcação não-manual nem sempre é realizada durante a produção de alguns sinais.

\section{Discussão}

A complexidade da variação nos sinais da libras se manifestou, entre outras coisas, em razão de muitos sinais variarem, contrariamente às nossas expectativas, em relação a mais de uma das categorias de variação apresentadas na sub-seção 4.2. Um exemplo disso é o sinal ALT@, para o qual atestamos pronúncias diferentes baseadas em parâmetros distintos. Uma dessas variantes consiste nas diferentes configurações que a mão ativa pode assumir: indicador em gancho (Figura 29a) ou distendido (demais casos).Além disso,o sinal ALT@ pode variar em relação à configuração da mão passiva (em 1 em (29b) e em B (29c)), na forma do movimento (circular e pra cima em (29a-d) ou só circular em (29e)), nas marcações não-manuais (com olhar para cima (Figuras 29a e 29c) ou sem, nos demais casos) e no número de mãos (com duas (Figura 29b e 29c) e com uma, nos demais casos). 


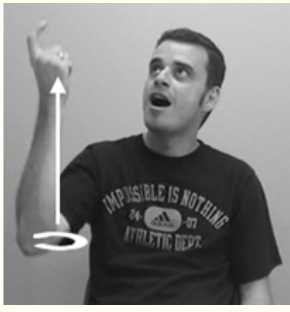

(a)

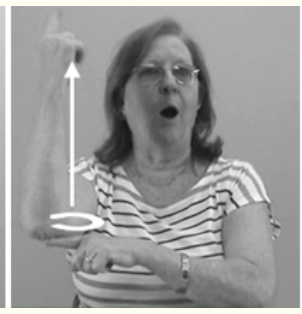

(b)

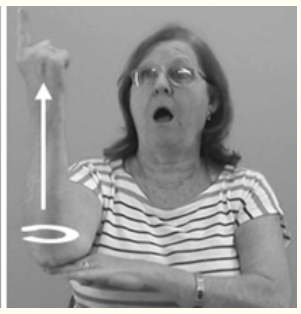

(c)

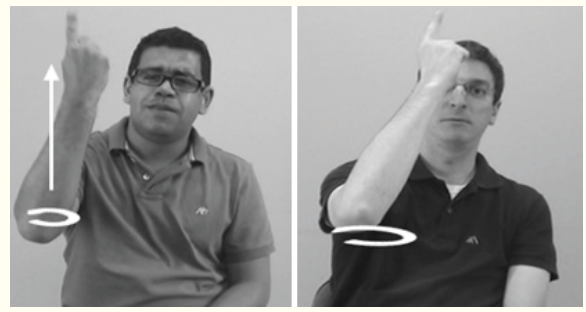

(d)

(e)

Figura 29: ALT@

Apesar disso, vale ressaltar, a nossa percepção inicial de que os sinais variariam em apenas um dos parâmetros considerados se mostrou válida para aproximadamente $50 \%$ de nossos estímulos, como mostra o gráfico em 11 (Figura 30).

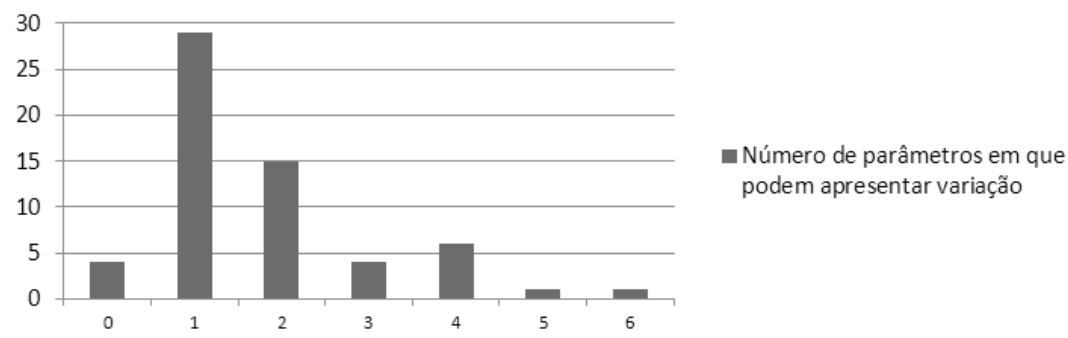

Figura 30: Frequência de sinais por número de parâmetros em que variaram

Além da variação em mais de um parâmetro, o gráfico acima também mostra uma outra situação não prevista: a de não variação. Esse foi o caso dos sinais BRINCAR, CHOCOLATE, ERRAD@ e 
NÃO-SABER, para os quais não atestamos nem a variação esperada, nem a variação nos outros parâmetros considerados.

Com exceção desses casos e de alguns outros poucos em que as variantes ocorreram com frequências parecidas, nossos resultados vão na mesma direção dos de Lucas et al. (2001), que reportam que, apesar da variabilidade na configuração de mão em 1 na ASL, algumas variantes são mais frequentes que outras. Como mostra a Tabela 7,0 teste-z de proporções realizado com o nível de significância fixado em 0,05 confirmou, para pelo menos $50 \%$ dos casos de variação em todos os parâmetros aqui considerados, a diferença na frequência de suas respectivas variantes, sinalizada pela estatística descritiva reportada na seção anterior ${ }^{23}$.

Tabela 7: Porcentagem dos casos em que a diferença na proporção das variantes foi estatisticamente significativa

\begin{tabular}{c|c} 
Parâmetro & $\begin{array}{c}\text { Percentagem de diferenças significativas entre as propor- } \\
\text { ções da frequência das variantes }\end{array}$ \\
\hline Configuração de mão & $65,4 \%$ \\
\hline Localização & $62,5 \%$ \\
\hline Movimento & $72,7 \%$ \\
\hline Face/Orientação & $55,5 \%$ \\
\hline Número de mãos & $71,5 \%$ \\
\hline Marcações Não-Manuais & $66,6 \%$
\end{tabular}

Como discutido na seção anterior, no entanto, as razões para essa diferença na frequência das variantes parecem ser diversas, dado que envolvem não somente facilidade de articulação ou conformidade a padrões da língua, mas também o tipo de sinal e fatores de natureza sociolinguística como, por exemplo, estigmatização de uma dada variante.

A análise de nossos dados também revelou a ocorrência de variação intra-sujeito. Apesar de esses casos terem se dado com todos os parâmetros aqui considerados, eles não foram tão frequentes quanto os casos de variação inter-sujeito (Tabela 8). Tal fato pode estar relavariação podem ser vistos nos anexos deste trabalho. 
cionado ao contexto de eliciação experimental, que é por si só mais formal, bem como ao tipo de tarefa solicitada aos sujeitos: produção de sinais isolados a partir da leitura de glosas em português.

Tabela 8: Casos de variação intra-sujeito

\begin{tabular}{|c|c|c|c|c|c|c|c|c|c|c|c|}
\hline Suj. & $\begin{array}{c}\text { Config. } \\
\text { (mão dom.) }\end{array}$ & $\begin{array}{l}1 \text { ou } 2 \\
\text { config. }\end{array}$ & Polegar & \begin{tabular}{c|} 
Dedo \\
mínimo
\end{tabular} & $\begin{array}{c}\text { Mão não- } \\
\text { dom. }\end{array}$ & Loc. & $\begin{array}{l}\text { Movi- } \\
\text { mento }\end{array}$ & $\begin{array}{l}\text { Or./ } \\
\text { face }\end{array}$ & $\begin{array}{l}\text { No. de } \\
\text { mãos }\end{array}$ & MNM & Total \\
\hline 1 & $\begin{array}{l}\text { BOBAGEM } \\
\text { ELEVADOR }\end{array}$ & $\begin{array}{l}\text { SOCIE- } \\
\text { DADE }\end{array}$ & & & & OURO & & & $\begin{array}{c}\text { PIPA } \\
\text { QUERER }\end{array}$ & $\begin{array}{c}\text { ALT@ } \\
\text { PIPA } \\
\text { ROUBAR }\end{array}$ & 9 \\
\hline 2 & & & NORMAL & & & & & & PIPA & PIPA & 3 \\
\hline 3 & & & $\begin{array}{l}\text { FARMÁ- } \\
\text { CIA }\end{array}$ & & & & & & $\begin{array}{l}\text { CARRI- } \\
\text { NHO }\end{array}$ & PIPA & 3 \\
\hline 4 & TAMBÉM & & & & $\begin{array}{c}\text { PROBLE- } \\
\text { MA }\end{array}$ & OURO & & & & & 3 \\
\hline 5 & & & NORMAL & & $\begin{array}{l}\text { PROBLE- } \\
\text { MA }\end{array}$ & $\begin{array}{l}\text { NÃO- } \\
\text { SABER }\end{array}$ & & & & PIPA & 4 \\
\hline 6 & $\begin{array}{l}\text { CARRINHO } \\
\text { NATAL } \\
\text { PESSOA }\end{array}$ & & & & $\begin{array}{c}\text { NÃO- } \\
\text { AGUEN- } \\
\text { TAR }\end{array}$ & & GORD@ & PRÓPRIO & NORMAL & ALT@ & 8 \\
\hline 7 & & & & & & AVIÃO & ALT@ & & ALT@ & ALT@ & 4 \\
\hline 8 & & & & & & & & $\begin{array}{l}\text { LÍNGUA- } \\
\text { DE-SINAIS }\end{array}$ & & PIPA & 2 \\
\hline 9 & & & & & VIDRO & OURO & $\begin{array}{l}\text { OITO } \\
\text { LEM- } \\
\text { BRAR }\end{array}$ & & & & 4 \\
\hline 10 & ELEVADOR & & & $\begin{array}{c}\text { BOBA- } \\
\text { GEM }\end{array}$ & & & & $\begin{array}{c}\text { LÍNGUA- } \\
\text { DE-SINAIS } \\
\text { PRÓPRIO } \\
\text { TRABA- } \\
\text { LHAR }\end{array}$ & NORMAL & GORD@ & 7 \\
\hline 11 & FARMÁCIA & & & & ALT@ & $\begin{array}{l}\text { ALÍVIO } \\
\text { QUERER }\end{array}$ & $\begin{array}{l}\text { CARRI- } \\
\text { NHO }\end{array}$ & TARDE & $\begin{array}{c}\text { MADRU- } \\
\text { GA-DA }\end{array}$ & GORD@ & 8 \\
\hline 12 & $\begin{array}{l}\text { CANCELAR } \\
\text { FUSCA } \\
\text { NATAL }\end{array}$ & & & $\begin{array}{l}\text { SACRI- } \\
\text { FÍCIO }\end{array}$ & $\begin{array}{c}\text { NÃO- } \\
\text { AGUEN- } \\
\text { TAR }\end{array}$ & & & & & $\begin{array}{c}\text { ESTA- } \\
\text { DOS- } \\
\text { UNIDOS }\end{array}$ & 6 \\
\hline Total & 11 & 1 & 3 & 2 & 6 & 7 & 5 & 6 & 8 & 12 & 61 \\
\hline
\end{tabular}

Além disso, a variação intra-sujeito não se deu de forma homogênea entre os parâmetros articulatórios aqui considerados. Como mostra a Tabela 9, alguns parâmetros (configuração de mão da mão dominante e marcações não-manuais (MNM)) concentraram mais casos de variação desse tipo do que outros. Além disso, ao que parece, a variação intra-sujeito também está suscetível à variação inter-sujeito, dado que alguns participantes apresentaram mais casos de variação dessa natureza do que outros.

Em suma, este trabalho, além de evidenciar a variação inter e intrasujeito na libras, também evidenciou a complexidade dessa variação, 
ao mostrar que um mesmo sinal pode variar em mais de um parâmetro articulatório. Um de nossos casos mais extremos é o sinal FUSCA (Figura 31), para o qual atestamos sete pronúncias diferentes.

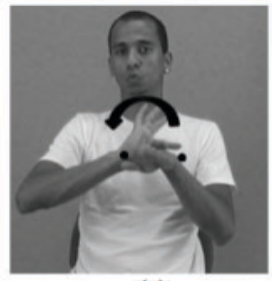

(a)

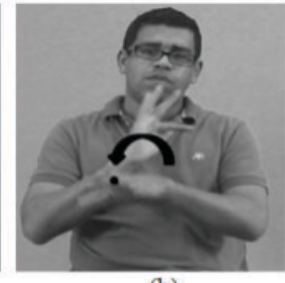

(b)

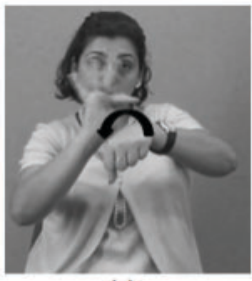

(c)

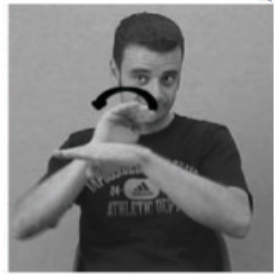

(d)

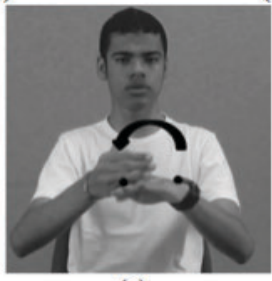

(e)

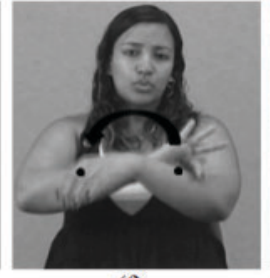

(f)

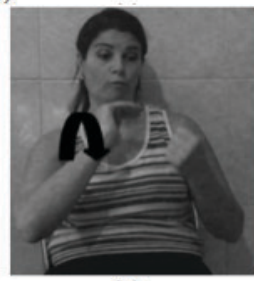

(g)

Figura 31: Diferentes pronúncias do sinal FUSCA. Os pontos representam a ocorrência de contato.

A análise de casos como este, no entanto, pode contribuir não apenas para um melhor entendimento da variação na libras, mas também lançar luz sobre suas unidades sublexicais e a sua relevância em termos perceptivos. Como sugere a descrição detalhada de FUSCA na Tabela 9, apesar da grande variabilidade na produção desse sinal, pode-se notar que o parâmetro movimento se mantém constante ${ }^{24}$. Isso deve sugerir que, ainda que um sinal varie muito em sua forma, algo nele precisa ser preservado para garantir a sua compreensão, tal como na articulação dos sons das línguas orais.

24. Isso não significa que o movimento foi produzido igualmente por todos os sujeitos. Apesar de em todos os casos termos observado sua forma arqueada, o movimento variou entre os participantes de nosso estudo no que diz respeito à sua iteração, amplitude, velocidade, etc. 
Tabela 9: Descrição das diferentes pronúncias do sinal FUSCA ${ }^{25}$

\begin{tabular}{|c|c|c|c|c|c|c|c|c|}
\hline $\begin{array}{c}\text { Figura } \\
\text { corres- } \\
\text { pondente }\end{array}$ & $\begin{array}{c}\text { Número } \\
\text { de } \\
\text { sujeitos }\end{array}$ & $\begin{array}{c}\text { Configuração } \\
\text { da } \\
\text { mão } \\
\text { dominante }\end{array}$ & $\begin{array}{c}\text { Configuração } \\
\text { da mão } \\
\text { não- } \\
\text { dominante }\end{array}$ & $\begin{array}{c}\text { Contato } \\
\text { inicial }\end{array}$ & $\begin{array}{c}\text { Contato } \\
\text { final }\end{array}$ & Localização & $\begin{array}{l}\text { Número } \\
\text { de mãos }\end{array}$ & Movimento \\
\hline $12 \mathrm{a}$ & 5 & $\begin{array}{c}\mathrm{F} \text { (polegar em } \\
\text { contato com a } \\
\text { lateral do } \\
\text { indicador, } \\
\text { dobrado na junta } \\
\text { proximal, demais } \\
\text { dedos abertos e } \\
\text { espalmados) }\end{array}$ & ? & + & + & $\begin{array}{l}\text { Pulso- } \\
\text { dedos }\end{array}$ & 2 & Arqueado \\
\hline $12 \mathrm{~b}$ & 1 & $\mathrm{~F}$ & B relaxado & - & + & $\begin{array}{l}\text { Pulso- } \\
\text { dedos }\end{array}$ & 2 & Arqueado \\
\hline $12 \mathrm{c}$ & 1 & $\mathrm{~F}$ & $\mathrm{~s}$ & - & - & $\begin{array}{l}\text { Pulso- } \\
\text { dedos }\end{array}$ & 2 & Arqueado \\
\hline $12 \mathrm{~d}$ & 1 & $\Leftrightarrow$ & $\Rightarrow$ & - & - & $\begin{array}{l}\text { Pulso- } \\
\text { dedos }\end{array}$ & 2 & Arqueado \\
\hline $12 \mathrm{e}$ & 2 & $\leftarrow$ & ? & + & + & $\begin{array}{l}\text { Pulso- } \\
\text { dedos }\end{array}$ & 2 & Arqueado \\
\hline $12 \mathrm{f}$ & 1 & \& & B relaxado & + & + & $\begin{array}{c}\text { Antebraço- } \\
\text { dedos }\end{array}$ & 2 & Arqueado \\
\hline $12 \mathrm{~g}^{29}$ & 1 & $\Leftrightarrow$ & - & - & - & $\begin{array}{l}\text { Espaço } \\
\text { neutro }\end{array}$ & 1 & Arqueado \\
\hline
\end{tabular}

\section{Conclusão}

Os resultados do experimento aqui reportado evidenciaram que a maior parte das variações na realização de sinais da libras, observada em sinalizações espontâneas, se manifestaram nas produções dos sujeitos deste estudo. Entretanto, nossos resultados mostraram que essa variação pode envolver não somente os sete parâmetros articulatórios que consideramos aqui, mas também outras características articulatórias como, por exemplo, (1) a realização ou não de contato entre os articuladores, (2) a flexão na junta proximal ou distal do ante-braço, (3) a repetição do movimento, (3) a presença ou não de movimento na mão não-dominante e (4) a oralização total ou parcial da palavra correspondente em português.

A quantificação das ocorrências das variantes dos sinais mostrou que algumas variantes são, em geral, mais frequentes do que outras, semelhantemente aos resultados de Lucas et al. (2001) em um estudo sobre a variação na configuração de mão em 1 na ASL. Conforme discutimos ao longo deste trabalho, as causas para a maior ou menor

25. Apesar de também haver variação na orientação da variante $12 \mathrm{~g}$ em relação às demais, por exiguidade de espaço, não incluímos esse parâmetro na tabela.

26. A sinalizadora produziu o sinal FUSCA como parte de um composto. Ela primeiramente realizou o sinal CARRO, articulado com as mãos em $\mathrm{S}$, e, na sequência, o sinal produzido pela maioria como FUSCA. A mão não-dominante aparece em $\mathrm{S}$ na imagem, porque ela perseverou a mão não-dominante do sinal anterior. 
frequência de algumas variantes parecem envolver fatores diversos tais como facilidade de articulação, tipo de sinal, conformidade a padrões da língua, avaliação sociolinguística, etc.

Além da variação inter-sujeito, este trabalho também evidenciou a ocorrência, ainda que em menor grau, de variação intra-sujeito, totalmente ignorada na literatura sobre a ASL que tomamos por base.

Deixamos para trabalhos futuros uma análise detalhada da variação em aspectos articulatórios não explorados neste artigo, bem como um estudo das possíveis correlações entre as variantes aqui descritas, a fim de verificar se estas apresentam alguma restrição de ocorrência em relação a outras.

Recebido em dezembro de 2013 Aprovado em maio de 2014 E-mails: andre.xavier.unicamp@gmail.com pabarbosa.unicampbr@gmail.com

\section{Referências bibliográficas}

AnN, Jean. "A functional explanation of Taiwan Sign Language Handshape Frequency”. Language and Linguistics 6.2: 217-246, 2005.

Battison, Robbin. "Phonological Deletion in American Sign Language". Sign Language Studies 5, pp. 1-19, 1974. ; MARKOWICZ, Harry; WOODWARD, James. "A good rule of thumb: Variable phonology in American Sign Language". In.: FASOLD, Ralph W.; SHUY, Roger W. (org.). Analyzing variation in language. Washing, D.C.: Georgetown University Press, 1975, pp. 291-302.

BRENNAN, Mary. "The Visual World of BSL: An Introduction". In.: BRIEN, David (org.). Dictionary of British Sign Language/English. London: Faber \& Faber, 1992, pp. 1-133.

BRENTARI, Diane; PADDEN, Carol. "Native and foreign vocabulary in American Sign Language: A lexicon with multiple origins". In.: BRENTARI, Diane. (org.). Foreign Vocabulary in Sign Languages: A Cross-linguistic Investigation of Word Formation. Mahwah, NJ: Lawrence Erlbaum Associates, 2001, pp. 87-119.

Felipe de SouZA, Tânia Amaral. A relação sintático-semântica dos verbos e seus argumentos na língua brasileira de sinais (libras). 1998. Tese (Doutorado em linguística) - Universidade Federal do Rio de Janeiro, Rio de Janeiro, 1998. 
Friedman, Lynn A. "Phonological Processes in the American Sign Language". Proceedings of the First Annual Meeting of the Berkeley Linguistics Society, 1975, pp. 147-159.

FrishberG, Nancy. Arbitrariness and Iconicity: Historical Change in American Sign Language, Language, vol. 51, no. 3, p. 696-719, 1975.

Hoopes, Rob. "A preliminary examination of pinky extension: Suggestions regarding its occurrence, constraints, and function". In.: LUCAS, Ceil. (org.). Pinky extension and eye gaze: Language use in Deaf communities, Washington, DC: Gallaudet University Press, pp. 3-17, 1998.

IsRael, Assaf; SANDLER, Wendy. "Phonological Category Resolution:

A Study of Handshapes in Younger and Older Sign Languages". In.: CHANNON, Rachel; VAN DER HULST, Harry. (org.). Formational Units in Sign Language, Nijmegen: Ishara, pp. 177-202, 2011.

Johnson, Robert. E.; LIDDELL, Scott K. "Toward a Phonetic Representation of Hand Configuration: The Fingers". Sign Language Studies 12, 1, Fall, 2011, pp. 5-45.

Johnston, Trevor; SCHEMBRI, Adam. Australian Sign Language (Auslan): An introduction to sign language linguistics. Cambridge: Cambridge University Press. 2007. 296 p.

KLIMA, Edward; BELLUGI, Ursulla. The Signs of Language, Cambridge,

MA.: Harvard University Press, 1979.

LIDDELL, Scott K. THINK and BELIEVE: sequentiality in American Sign Language. Language 60, v.2, 372-399, 1984.

LidDELL, Scott K.; JOHNSON, Robert E. “American Sign Language: The

Phonological Base” Sign Language Studies 64, pp. 197-277, 1989.

Lucas, Ceil; et al. Sociolinguistic variation in American Sign Language.

Washington, DC: Gallaudet University Press, 2001.

PAdDEN, Carol; PERLMUTTER, David. "American Sign Language and the Architecture of Phonological Theory". Natural Language and Linguistic Theory 5, 3, pp. 335-75, 1987.

SANDLER, Wendy. "Symbiotic symbolization by hand and mouth in sign language". Semiotica 174 (1/4), pp. 241-275, 2009.

Stokoe, William. "Sign Language Structure: An Outline of the Visual Communication Systems of the American Deaf". Studies in Linguistics: Occasional Papers, 8, Washington, DC: Gallaudet University Press, 1960.

WoODWARD, James C.; et al. "Facing and handling variation in American Sign Language phonology". Sign Language Studies 10, pp. 43-51, 1976. 
; DESANTIS, Susan. "Two to One It Happens: Dynamic Phonology in Two Sign Languages". Sign Language Studies 17, pp. 329 -46, 1977.

XAVIER, André Nogueira. Descrição fonético-fonológica dos sinais da língua brasileira de sinais (libras). 2006. 175 f. Dissertação (Mestrado em Linguística). Faculdade de Filosofia, Letras e Ciências Humanas, Universidade de São Paulo, São Paulo, 2006.

. "Variação fonológica na libras: um estudo da alternância no número de articuladores manuais envolvidos na produção dos sinais". In: XVI SETA - Seminários de Teses em Andamento, 2011, Campinas. Anais do SETA (UNICAMP), 2011. v. 5. p. 119-145.

. "Doubling of the number of hands as a resource for the expression of meaning intensification in Brazilian Sign Language (Libras)". Journal of Speech Sciences, v. 1, p. 169-181, 2013.

. "Uma ou duas? Eis a questão! Um estudo do parâmetro número de mãos na produção de sinais da língua brasileira de sinais (libras)". 2014. 158 f. Tese (Doutorado em Linguística). Instituto de Estudos da Linguagem, Universidade Estadual de Campinas, Campinas, 2014.

XAVIER, André Nogueira; BARBOSA, Plínio Almeida. "A preliminary study on the production of signs in Brazilian Sign Language when one of the manual articulators is unavailable". Proceedings of the 12 th Annual Conference of the International Speech Communication Association (Interspeech), pp. 645-648, 2011. 


\section{Anexo: resultados do teste-z de proporções $(\alpha=0.05)$}

\begin{tabular}{|c|c|c|c|c|c|c|}
\hline Parâmetro & Sinal & Variante 1 & Variante 2 & Variante 3 & $x^{2}$ & P-valor \\
\hline \multirow{18}{*}{$\begin{array}{l}\text { Configurações de } \\
\text { mão nativas }\end{array}$} & AVIÃO & 12 & 0 & & 20.1 & $<0,001^{*}$ \\
\hline & PREOCUPAD@ & 11 & 1 & & 13.5 & $<0,001 *$ \\
\hline & SILÊNCIO & 11 & 1 & & 13.5 & $<0,001^{*}$ \\
\hline & VERDADE & 11 & 1 & & 13.5 & $<0,001^{*}$ \\
\hline & NÃO-AGUENTAR & 11 & 1 & & 13.5 & $<0,001^{*}$ \\
\hline & LETRA-X & 9 & 1 & & 9.8 & $<0,001^{*}$ \\
\hline & ALT@ & 9 & 3 & & 4.1 & $0.04 *$ \\
\hline & CANCELAR & 9 & 2 & 1 & 14.2 & $<0,001^{*}$ \\
\hline & EMPRESA & 9 & 2 & & 6.5 & $0.01^{*}$ \\
\hline & SUPERMERCADO & 7 & 5 & & 0.1 & 0.68 \\
\hline & SALÁRIO & 7 & 5 & & 0.1 & 0.68 \\
\hline & ELEVADOR & 7 & 2 & 2 & 6.8 & $0.03^{*}$ \\
\hline & ENTENDER & 7 & 5 & & 0.1 & 0.68 \\
\hline & TAMBÉM & 6 & 6 & & 0 & 1 \\
\hline & BOBAGEM & 6 & 2 & & 2.2 & 0.13 \\
\hline & DESCOBRIR & 6 & 3 & & 0.8 & 0.34 \\
\hline & NATAL & 5 & 3 & 2 & 2.1 & 0.34 \\
\hline & ÔNIBUS & 4 & 1 & & 1.6 & 0.20 \\
\hline \multirow{8}{*}{$\begin{array}{c}\text { Configurações } \\
\text { nativas vs. inicia- } \\
\text { lizadas }\end{array}$} & FUSCA & 8 & 4 & & 1.5 & 0.22 \\
\hline & PESSOA & 6 & 6 & & 0 & 1 \\
\hline & DESCOBRIR & 3 & 9 & & 4.1 & $0.04^{*}$ \\
\hline & TEXTO & 2 & 10 & & 8.1 & $<0,001^{*}$ \\
\hline & FALS@ & 2 & 10 & & 8.1 & $<0,001^{*}$ \\
\hline & ELEVADOR & 1 & 11 & & 13.5 & $<0,001^{*}$ \\
\hline & EMPRESA & 1 & 11 & & 13.5 & $<0,001^{*}$ \\
\hline & RESPEITAR & 1 & 10 & & 11.6 & $<0,001^{*}$ \\
\hline \multirow{4}{*}{$\begin{array}{c}\text { Duas ou uma } \\
\text { configuração (mu- } \\
\text { dança de CM) }\end{array}$} & SOCIEDADE & 3 & 9 & & 4.1 & $0.04 *$ \\
\hline & LETRA-X & 2 & 10 & & 8.1 & $<0,001^{*}$ \\
\hline & NATAL & 2 & 10 & & 8.1 & $<0,001^{*}$ \\
\hline & SHOPPING & 1 & 11 & & 13.5 & $<0,001^{*}$ \\
\hline \multirow{5}{*}{$\begin{array}{c}\text { Distenção ou não } \\
\text { do polegar }\end{array}$} & BRINCAR & 12 & 0 & & 20.1 & $<0,001^{*}$ \\
\hline & ÔNIBUS & 7 & 4 & & 0.7 & 0.39 \\
\hline & FARMÁCIA & 3 & 9 & & 4.1 & $0.04 *$ \\
\hline & NORMAL & 2 & 10 & & 8.1 & $<0,001^{*}$ \\
\hline & CHOCOLATE & 0 & 12 & & 20.1 & $<0,001^{*}$ \\
\hline \multirow{2}{*}{$\begin{array}{l}\text { Distenção ou não } \\
\text { do dedo mínimo }\end{array}$} & BOBAGEM & 3 & 7 & & 1.8 & 0.17 \\
\hline & SACRIFÍCIO & 1 & 11 & & 13.5 & $<0,001^{*}$ \\
\hline Metátese & COMPRAR & 4 & 8 & & 1.5 & 0.22 \\
\hline \multirow{7}{*}{$\begin{array}{l}\text { Sinais assimétricos } \\
\text { cuja mão não- } \\
\text { dominante pode } \\
\text { assimilar a CM da } \\
\text { dominante }\end{array}$} & TEXTO & 10 & 2 & & 8.1 & $<0,001^{*}$ \\
\hline & METRÔ & 9 & 2 & & 6.5 & $0.01 *$ \\
\hline & NÃO-AGUENTAR & 3 & 8 & & 2.9 & 0.08 \\
\hline & SOCIEDADE & 2 & 10 & & 8.1 & $<0,001^{*}$ \\
\hline & PROBLEMA & 2 & 2 & 8 & 9 & $0.01 *$ \\
\hline & ALT@ & 1 & 1 & & 0 & 1 \\
\hline & PIPA & 1 & 1 & & 0 & 1 \\
\hline
\end{tabular}




\begin{tabular}{|c|c|c|c|c|c|c|}
\hline Parâmetro & Sinal & Variante 1 & Variante 2 & Variante 3 & $x^{2}$ & P-valor \\
\hline \multirow{7}{*}{$\begin{array}{l}\text { Sinais assimétricos } \\
\text { que apresentam } \\
\text { diferentes confi- } \\
\text { gurações na mão } \\
\text { não-dominante }\end{array}$} & ERRAD@ & 12 & 0 & & 20.1 & $<0,001^{*}$ \\
\hline & VIDRO & 9 & 2 & & 6.5 & $0.01 *$ \\
\hline & FUSCA & 9 & 2 & & 6.5 & $0.01 *$ \\
\hline & AJUDAR & 8 & 4 & & 1.5 & 0.22 \\
\hline & MADRUGADA & 2 & 4 & 2 & 1.5 & 0.47 \\
\hline & METRÔ & 1 & 1 & & 0 & 1 \\
\hline & DESCOBRIR & 1 & & & & \\
\hline \multirow{3}{*}{$\begin{array}{l}\text { Localização alta - } \\
\text { localização baixa }\end{array}$} & LEMBRAR & 6 & 5 & 1 & 5.2 & 0.07 \\
\hline & OURO & 2 & 1 & 8 & 11.7 & $0.002^{*}$ \\
\hline & ALÍVIO & 1 & 6 & 4 & 5.1 & 0.07 \\
\hline \multirow{5}{*}{$\begin{array}{l}\text { Diferentes locali- } \\
\text { zações }\end{array}$} & GORD@ & 11 & 1 & & 13.5 & $<0,001 *$ \\
\hline & FUSCA & 10 & 1 & 1 & 20.2 & $<0,001^{*}$ \\
\hline & AVIÃO & 9 & 2 & 1 & 14.2 & $<0,001^{*}$ \\
\hline & QUERER & 8 & 2 & 2 & 9 & $0.01 *$ \\
\hline & LETRA-X & 7 & 5 & & 0.1 & 0.68 \\
\hline \multirow{2}{*}{$\begin{array}{l}\text { Com ou sem } \\
\text { movimento }\end{array}$} & GOSTAR & 6 & 1 & & 4.5 & $0.03^{*}$ \\
\hline & OITO & 3 & 9 & & 4.1 & $0.04 *$ \\
\hline \multirow{9}{*}{$\begin{array}{c}\text { Diferentes tipos de } \\
\text { movimento }\end{array}$} & TÍTULO & 10 & 1 & 1 & 20.2 & $<0,001^{*}$ \\
\hline & EMPRESA & 11 & 1 & & 13.5 & $<0,001 *$ \\
\hline & AVIÃO & 11 & 1 & & 13.5 & $<0,001 *$ \\
\hline & CARRINHO & 9 & 2 & 1 & 14.2 & $<0,001^{*}$ \\
\hline & GORD@ & 8 & 4 & & 1.5 & 0.22 \\
\hline & ALT@ & 9 & 3 & & 4.1 & $0.04 *$ \\
\hline & TRABALHAR & 9 & 2 & 1 & 14.2 & $<0,001^{*}$ \\
\hline & LÍNGUA-DE-SINAIS & 8 & 4 & & 1.5 & 0.22 \\
\hline & \begin{tabular}{|c|} 
SHOPPING \\
\end{tabular} & 6 & 5 & 1 & 5.2 & 0.07 \\
\hline \multirow{9}{*}{ Face-orientação } & LETRA-A & 10 & 2 & & 8.1 & $0.004 *$ \\
\hline & TRABALHAR & 10 & 1 & 1 & 24 & $<0,001^{*}$ \\
\hline & $\begin{array}{c}\text { ELEVADOR } \\
\text { (mão não-dominante) }\end{array}$ & 9 & 3 & & 4. & $0.04 *$ \\
\hline & EMPRESA & 8 & 3 & 1 & 9.7 & $0.007 *$ \\
\hline & LETRA-X & 8 & 3 & 1 & 9.7 & $0.007 *$ \\
\hline & $\begin{array}{c}\text { PROIBID@ } \\
\text { (mão não-dominante) } \\
\end{array}$ & 7 & 4 & 1 & 6.7 & 0.03 \\
\hline & $\begin{array}{c}\text { TARDE } \\
\text { (mão dominante) } \\
\end{array}$ & 7 & 3 & 2 & 5.2 & 0.07 \\
\hline & $\begin{array}{c}\text { TEXTO } \\
\text { (mão não-dominante) }\end{array}$ & 5 & 4 & 3 & 0.7 & 0.68 \\
\hline & $\begin{array}{c}\text { PRÓPRIO } \\
\text { (mão não-dominante) }\end{array}$ & 5 & 5 & 2 & 2.2 & 0.32 \\
\hline \multirow{14}{*}{$\begin{array}{l}\text { Número } \\
\text { de mãos }\end{array}$} & NORMAL & 12 & 0 & & 20.1 & $<0,001^{*}$ \\
\hline & PIPA & 10 & 2 & & 8.1 & $0.004 *$ \\
\hline & ALT@ & 9 & 3 & & 4.1 & $0.04 *$ \\
\hline & QUERER & 9 & 3 & & 4.1 & $0.04 *$ \\
\hline & PORTO-ALEGRE & 8 & 2 & & 5 & $0,02 *$ \\
\hline & TARDE & 8 & 4 & & 1.5 & 0.22 \\
\hline & CARRINHO & 7 & 5 & & 0.1 & 0.68 \\
\hline & CAFÉ & 7 & 5 & & 0.1 & 0.68 \\
\hline & MADRUGADA & 5 & 7 & & 0.1 & 0.68 \\
\hline & ACEITAR & 2 & 10 & & 8.1 & $0.004 *$ \\
\hline & ROUBAR & 1 & 11 & & 13.5 & $<0,001^{*}$ \\
\hline & FUSCA & 1 & 11 & & 13.5 & $<0,001 *$ \\
\hline & PRECISAR & 1 & 11 & & 13.5 & $<0,001 *$ \\
\hline & ELEVADOR & 1 & 10 & & 11.6 & $<0,001 *$ \\
\hline
\end{tabular}




\begin{tabular}{|c|c|c|c|c|c|c|}
\hline Parâmetro & Sinal & Variante 1 & Variante 2 & Variante 3 & Х2 & P-valor \\
\hline \multirow{4}{*}{$\begin{array}{c}\text { Marcação não- } \\
\text { manual }\end{array}$} & ROUBAR & 9 & 3 & & 4.1 & $0.04 *$ \\
\cline { 2 - 7 } & CARRINHO & 8 & 4 & & 1.5 & 0.22 \\
\cline { 2 - 7 } & EUA & 7 & 5 & & 0.1 & 0.68 \\
\cline { 2 - 7 } & ALT@ & 6 & 6 & & 0 & 1 \\
\cline { 2 - 7 } & PIPA & 4 & 8 & & 1.5 & 0.22 \\
\cline { 2 - 7 } & GORD@ & 1 & 11 & & 13.5 & $<0,001^{*}$ \\
\hline
\end{tabular}

